Article

\title{
Profiling of Primary Metabolites and Volatile Determinants in Mahlab Cherry (Prunus mahaleb L.) Seeds in the Context of Its Different Varieties and Roasting as Analyzed Using Chemometric Tools
}

\author{
Mohamed A. Farag 1,2,*, Amira R. Khattab ${ }^{3}$, Samir Shamma ${ }^{4}$ and Sherif M. Afifi ${ }^{5}$ \\ 1 Pharmacognosy Department, College of Pharmacy, Cairo University, Kasr El Aini St., Cairo 11562, Egypt \\ 2 Chemistry Department, School of Sciences \& Engineering, The American University in Cairo, \\ New Cairo 11835, Egypt \\ 3 Pharmacognosy Department, College of Pharmacy, Arab Academy for Science, Technology and Maritime \\ Transport, Alexandria 1029, Egypt; Dr_amira_khattab@aast.edu \\ 4 Institute of Global Health and Human Ecology, School of Sciences and Engineering, The American University \\ in Cairo, P.O. Box 74, New Cairo 11835, Egypt; samirnabhan@aucegypt.edu \\ 5 Pharmacognosy Department, Faculty of Pharmacy, University of Sadat City, Sadat City 32897, Egypt; \\ shshsh38@hotmail.com \\ * Correspondence: Mohamed.farag@pharma.cu.edu.eg; Tel.: +20-2-236-2245; Fax: +20-2-2532-0005
}

Citation: Farag, M.A.; Khattab, A.R.; Shamma, S.; Afifi, S.M. Profiling of Primary Metabolites and Volatile Determinants in Mahlab Cherry (Prunus mahaleb L.) Seeds in the Context of Its Different Varieties and Roasting as Analyzed Using Chemometric Tools. Foods 2021, 10, 728. https://doi.org/10.3390/ foods 10040728

Academic Editor: Maria Cecilia do Nascimento Nunes

Received: 4 February 2021

Accepted: 24 March 2021

Published: 30 March 2021

Publisher's Note: MDPI stays neutral with regard to jurisdictional claims in published maps and institutional affiliations.

Copyright: (c) 2021 by the authors. Licensee MDPI, Basel, Switzerland. This article is an open access article distributed under the terms and conditions of the Creative Commons Attribution (CC BY) license (https:/ / creativecommons.org/licenses/by/ $4.0 /)$.

\begin{abstract}
Mahlab cherry (Prunus mahaleb L.) is a plant native to the Mediterranean basin and Eastern Europe, with several health benefits and culinary uses. We explored the compositional heterogeneity in the aroma profile and nutrients of three P. mahaleb seeds in the context of its cultivar type, i.e., white and red, and in response to roasting. A holistic untargeted metabolomics approach was employed for the first time using solid-phase microextraction (SPME-GC-MS) profiles of seed volatiles and primary metabolites coupled with chemometrics. Around 65 peaks belonging to sugars, fatty acids, esters and organic acids were identified by GC-MS. White mahlab from Egypt is rich in fatty acids, e.g., oleic and $\alpha$-linolenic acids. Some acyl esters, e.g., glycerylmonostearate and $n$-butylcaprylate, characterized mahlab cultivars from various origins. A total of 135 volatiles were identified, with organic acids and aldehydes the most abundant. Aldehydes were the most discriminatory in seed origin and in accounting for its distinct aroma. Several roasting indices were identified, viz. 1octanol, $\gamma$-caprolactone and isomintlactone. A direct relationship between furans and fatty acids was rationalized by cyclic transformation of the latter into furan derivatives. This study provides the first chemical evidence supporting the nutritional and flavor determinants of mahlab seeds, suggesting novel uses as a functional food.
\end{abstract}

Keywords: solid-phase microextraction (SPME); metabolomics; Prunus mahaleb L.; white and red mahlab; GC-MS; volatile profiling; roasting

\section{Introduction}

Mahlab or mahaleb cherry tree (Prunus mahaleb L. a member of family Rosaceae), also known as St. Lucie cherry, is found wild throughout the Mediterranean zone, as well as Eastern Europe and West Asia. It is cultivated for producing a highly valued global spice derived from the seeds contained within the cherry stones that is used to season sweet confections in Eastern Mediterranean countries. The powdered mahlab seed is used in small quantities to flavor food in Greece, Armenia and Turkey [1].

In Sudan, crushed kernels of white mahlab are used to manufacture traditional fragrances and for nourishing hair lotions in wedding preparations. In addition, consumption of soaked white mahlab seed is considered a remedy for the treatment of diarrhea in children [2]. The kernel oil has been exploited in specialty wines and liqueur, owing to its unique aroma. The kernel's flavor is comparable to that of a bitter almond taste, particularly 
after chewing, with a pleasant aroma widely used in small quantities to flavor foods, such as bagels, pastries, biscuits, cupcakes, candies and cookies. Mahlab kernel is considered as a vital source of protein (28\%) and carbohydrates (14\%). In addition, its oil (31\%) is incorporated in the manufacture of varnishes, specialty wines and lacquers. Traditionally, mahlab (St. Lucie cherry) kernels were used as tonics, diuretics, digestive aids, sedatives and antidiabetics [2]. Mahlab cherry exhibits anti-inflammatory and antioxidant activities, as well as antifungal and antibacterial effects, with decoctions made from different parts of the mahlab tree used locally for the treatment of asthma and the common cold [3].

The pleasant aroma and medicinal value of mahlab seed is attributed to its abundance in coumarins, such as herniarin and dihydrocoumarin, in addition to tannins and traces of cyanogenic glycosides [2]. Shams (2006) isolated a novel compound, namely $2-$ glucosyloxy-4-methoxy methyl trans cinnamate, from mahlab kernel, with seeds found rich in phenolic acids, e.g., $o$-coumaric acid glucosides, in addition to flavanols, e.g., quercetin3-O-glucoside [4]. Shams and Schmidt (2007) reported that mahlab seed oil is dominated by linoleic, $\alpha$-eleostearic and oleic acid in addition to tocopherols, i.e., $\gamma$-tocopherol, also accounting for its antioxidant effects [5]. The volatile composition derived from mahlab honey revealed high vomifoliol and coumarin levels likely derived from the plant itself [6]. With regard to differences among mahlab cultivars, white mahlab ( $P$. mahaleb) seeds are richer in oil and protein and, hence, are preferred compared to black mahlab (Monechma ciliatum) seeds [2]; other differences in its metabolite composition have been suggested but are yet to be fully elucidated. Concerning the genus Prunus, this is the first metabolomics approach to address its different varieties, in addition to the impact of roasting. Our aim is to assess the compositional heterogeneity in the aroma profile and nutrients of Prunus mahaleb seeds in the context of its cultivar type and in response to roasting.

Analysis of food and spices has lately started to implement modern analytical approaches, e.g., metabolomics, where samples are examined in a rather untargeted, comprehensive manner. GC-MS analysis has been extensively adopted for metabolomics profiling in fruits and seeds to characterize their metabolite components, e.g., volatiles and non-volatiles [7]. Unlike common thermal methods for volatile extraction, e.g., distillation, solid-phase microextraction (SPME) is a convenient analytical technique that is solvent-free and requires minimal sample preparation for the enhancement of volatile recovery from gas or liquid samples throughout a fused-silica fiber accompanied by the eventual desorption of these analytes [8]. To better interpret such huge datasets, multivariate data analyses are often used, e.g., principal component analysis (PCA), in addition to supervised methods, viz., orthogonal projection to least squares discriminant analysis (OPLS-DA), which can simplify metabolite data complexity and ease sample classification.

To the best of our knowledge, this is the first report of the determination of the quality characteristics of Prunus mahaleb seeds, i.e., aroma and nutrient metabolites, in the context of different cultivars and post-roasting using GC-MS, assisted by multivariate data analysis tools. For aroma collection, headspace SPME was used as a more sensitive method for volatile analysis.

\section{Materials and Methods}

\subsection{Plant Material}

Prunus mahaleb L. seeds were obtained from Egypt, harvested in late summer during the year of 2019 [9]; in addition, commercial samples were obtained from Greece and Sudan, with sample information presented in Table 1 . The powdered seeds were roasted by wrapping $5 \mathrm{~g}$ in aluminum foil and then heating them on a heating mantle at $180{ }^{\circ} \mathrm{C}$ for 15-20 min. A voucher specimen was deposited at the College of Pharmacy Herbarium, Cairo University, Cairo, Egypt. Each specimen was analyzed in triplicate by grinding separately $20 \mathrm{~g}$ of seeds to assess for biological variance. 
Table 1. Origins of the different $P$. mahaleb seed accessions used in analysis.

\begin{tabular}{ccc}
\hline Sample Codes & Seed Color & Location \\
\hline WG & White & Greece (Athens) \\
WE & White & Egypt (Cairo) \\
WS & White & Sudan (Khartoum) \\
RWS & Roasted white & Sudan (Khartoum) \\
RE & Red & Egypt (Cairo) \\
RRE & Roasted red & Egypt (Cairo) \\
RS & Red & Sudan (Khartoum) \\
RRS & Roasted red & Sudan (Khartoum) \\
\hline
\end{tabular}

\subsection{SPME and Chemicals}

SPME fibers of stable flex coated with divinylbenzene/carboxen/polydimethylsiloxane (DVB/CAR/PDMS, 50/30 $\mu \mathrm{m}$ ) or PDMS (polydimethylsiloxane) were purchased from Supelco (Oakville, ON, Canada). All other chemicals, volatile standards and sugars were purchased from Sigma Aldrich (St. Louis, MO, USA).

\subsection{GC-MS Analysis of Silylated Primary Metabolites}

Primary metabolite analysis was carried out as follows. Briefly, $100 \mathrm{mg}$ of finely powdered seeds (unroasted/roasted) was extracted with $5 \mathrm{~mL} \mathrm{100 \%} \mathrm{methanol} \mathrm{with} \mathrm{son-}$ ication for $30 \mathrm{~min}$ and frequent shaking, succeeded by centrifugation at $12,000 \times \mathrm{g}$ for $10 \mathrm{~min}$ to remove debris. For evaluation of biological replicates, 3 different samples for each $P$. mahaleb seed accession were analyzed under the same conditions. Then, $100 \mu \mathrm{L}$ of the methanol extract was aliquoted in screw-cap vials and left to evaporate under a nitrogen gas stream until complete dryness. For derivatization, $150 \mu \mathrm{L}$ of $\mathrm{N}$-methyl$N$-(trimethylsilyl)-trifluoroacetamide (MSTFA) previously diluted $1 / 1 \%$ with anhydrous pyridine was mixed with the dried methanol extract and incubated for $45 \mathrm{~min}$ at $60{ }^{\circ} \mathrm{C}$ prior to analysis using GC-MS. Separation of silylated derivatives was achieved on a Rtx-5MS (30-m length, 0.25-mm inner diameter and 0.25-m film) [10]. The protocol to validate silylation was adopted as previously reported [11].

\subsection{SPME-GC-MS Volatile Analysis}

Dried, finely powdered seeds (unroasted/roasted) $(20 \mathrm{mg})$ were placed in SPME screw-cap vials $(1.5 \mathrm{~mL})$ spiked with $10 \mu \mathrm{g}(Z)$-3-hexenyl acetate with fibers inserted manually above and placed in an oven kept at $50^{\circ} \mathrm{C}$ for $30 \mathrm{~min}$. HS-SPME analysis of the volatile compounds was performed as reported in [10] with slight modifications. The fiber was subsequently withdrawn into the needle and then injected manually into the injection port of a gas chromatography-mass spectrometer (GC-MS). GC-MS analysis was adopted on an Agilent 5977B GC/MSD equipped with a DB-5 column $(30 \mathrm{~m} \times 0.25 \mathrm{~mm}$ i.d. $\times 0.25$ $\mu \mathrm{m}$ film thickness; Supelco) and coupled to a quadrupole mass spectrometer. The interface and the injector temperatures were both set at $220^{\circ} \mathrm{C}$. Volatile elution was carried out using the following gradient temperature program: oven was set at $40^{\circ} \mathrm{C}$ for $3 \mathrm{~min}$, then increased to $180^{\circ} \mathrm{C}$ at a rate of $12{ }^{\circ} \mathrm{C} / \mathrm{min}$, kept at $180^{\circ} \mathrm{C}$ for $5 \mathrm{~min}$, finally increased at a rate of $40{ }^{\circ} \mathrm{C} / \mathrm{min}$ to $240{ }^{\circ} \mathrm{C}$ and kept at this temperature for $5 \mathrm{~min}$. Helium was utilized as a carrier gas with a total flow rate of $0.9 \mathrm{~mL} / \mathrm{min}$. For ensuring complete elution of volatiles, SPME fiber was prepared for the next analysis by placing it in the injection port at $220^{\circ} \mathrm{C}$ for $2 \mathrm{~min}$. For assessment of biological replicates, three different samples for each $P$. mahaleb seed accession were analyzed under the same conditions. Blank runs were made during sample analyses. The mass spectrometer was adjusted to EI mode at $70 \mathrm{eV}$ with a scan range set at $m / z 40-500$. 


\subsection{Metabolite Identification and Multivariate Data Analyses}

Identification of volatile and non-volatile silylated components was performed by comparing their retention indices (RI) in relation to n-alkanes (C6-C20), mass matching to NIST, WILEY library database and with standards if available. Peaks were first deconvoluted using AMDIS software (www.amdis.net (accessed on 28 November 2019)) [12] before mass spectral matching. Peak abundance data were exported for multivariate data analysis by extraction using MET-IDEA software (Broeckling, Reddy, Duran, Zhao, \& Sumner, 2006). Data were then normalized to the amount of spiked internal standard ( $Z$ )-3-hexenyl acetate and then subjected to principal component analysis (PCA), hierarchical clustering analysis (HCA) and partial least squares discriminant analysis (OPLS-DA) using SIMCA-P version 13.0 software package (Umetrics, Umeå, Sweden). Markers were subsequently identified by analyzing the S-plot, which was declared with covariance (p) and correlation (pcor). All variables were mean-centered and scaled to Pareto variance. Model validation was assessed by computing the diagnostic indices, viz. Q2 and R2 values, and permutation testing.

\section{Results and Discussion}

The goal of this study was to explore the metabolome diversity within cultivars of white and red mahlab seeds obtained from Greece, Egypt and Sudan (Table 1) and to further determine roasting impact on their metabolite makeup, i.e., nutrient non-volatiles and aroma compounds, aided by chemometric tools. For the assessment of the biological variance within each specimen and analysis conditions, three independent biological replicates were simultaneously analyzed by GC-MS.

\subsection{Primary Metabolite Profiling of Roasted/Unroasted Mahlab Seeds via GC-MS Analysis (Post-Silylation)}

To provide an overview of primary metabolites accounting for seeds' nutritional value and organoleptic features (Table 1), GC-MS analysis was employed post-silylation. A total of 65 peaks (Table 2, Figure 1) were annotated, including sugars (mono- and disaccharides), fatty acids, esters, organic acids and alcohols, in addition to a few amino acids and nitrogenous compounds. 
Table 2. Relative percentage of silylated metabolites in P. mahaleb seeds analyzed via GC-MS, $n=3$. For codes, refer to Table 1 .

\begin{tabular}{|c|c|c|c|c|c|c|c|c|c|c|c|}
\hline No. & Rt (min) & KI & Name & WG & WE & WS & RWS & RE & RRE & RS & RRS \\
\hline & Organic acids & & & & & & & & & & \\
\hline 1 & 7.062 & 1084.3 & Glycolic acid (2TMS) & $0.02 \pm 0.01$ & $0.04 \pm 0.01$ & $0.01 \pm 0.01$ & $0.33 \pm 0.28$ & $0.05 \pm 0.01$ & $0.33 \pm 0.02$ & $0.02 \pm 0.01$ & $0.04 \pm 0.01$ \\
\hline 2 & 7.531 & 1111.8 & Oxalic acid (2TMS) & $0.16 \pm 0.08$ & $0.55 \pm 0.01$ & $0.09 \pm 0.07$ & $0.18 \pm 0.09$ & $0.30 \pm 0.04$ & $0.59 \pm 0.21$ & $0.15 \pm 0.01$ & $0.25 \pm 0.11$ \\
\hline 3 & 9.764 & 1241.9 & $\gamma$-Hydroxybutyric acid (2TMS) & $0.04 \pm 0.02$ & $0.17 \pm 0.01$ & $0.01 \pm 0.01$ & $0.04 \pm 0.01$ & $0.11 \pm 0.01$ & $0.23 \pm 0.03$ & $0.03 \pm 0.01$ & $0.07 \pm 0.03$ \\
\hline 4 & 10.980 & 1321.4 & Succinic acid (2TMS) & $0.04 \pm 0.01$ & $0.10 \pm 0.01$ & $0.02 \pm 0.01$ & $0.08 \pm 0.03$ & $0.36 \pm 0.02$ & $0.57 \pm 0.06$ & $0.24 \pm 0.06$ & $0.37 \pm 0.23$ \\
\hline 5 & 13.526 & 1500.9 & Malic acid (3TMS) & $0.23 \pm 0.27$ & $0.16 \pm 0.07$ & $0.02 \pm 0.01$ & $0.04 \pm 0.02$ & $4.73 \pm 0.18$ & $7.43 \pm 0.35$ & $0.32 \pm 0.11$ & $0.48 \pm 0.13$ \\
\hline 6 & 14.127 & 1546.5 & Unknown acid & $0.06 \pm 0.02$ & $0.13 \pm 0.01$ & - & $0.01 \pm 0.00$ & $0.12 \pm 0.01$ & $0.20 \pm 0.01$ & $0.01 \pm 0.00$ & $0.02 \pm 0.01$ \\
\hline 7 & 17.210 & 1800.1 & Terephthalic acid (2TMS) & $0.04 \pm 0.01$ & $0.15 \pm 0.05$ & $0.02 \pm 0.01$ & $0.15 \pm 0.02$ & $0.08 \pm 0.01$ & $0.28 \pm 0.05$ & $0.12 \pm 0.02$ & $0.15 \pm 0.03$ \\
\hline 8 & 18.699 & 1941.2 & Unknown acid & $0.32 \pm 0.42$ & $0.27 \pm 0.13$ & $0.03 \pm 0.02$ & $0.12 \pm 0.03$ & $0.13 \pm 0.03$ & $0.05 \pm 0.01$ & $1.95 \pm 0.26$ & $0.13 \pm 0.01$ \\
\hline & Alcohols & & & & & & & & & & \\
\hline 9 & 10.429 & 1285.9 & Glycerol (3TMS) & $2.96 \pm 0.48$ & $7.41 \pm 0.66$ & $0.32 \pm 0.17$ & $0.53 \pm 0.14$ & $3.75 \pm 0.22$ & $5.01 \pm 0.39$ & $5.36 \pm 1.26$ & $6.88 \pm 3.69$ \\
\hline \multirow[t]{3}{*}{10} & 16.966 & 1780.1 & Glycerol-3-phosphate (4TMS) & - & $0.05 \pm 0.01$ & $0.01 \pm 0.01$ & $0.03 \pm 0.00$ & - & $0.01 \pm 0.00$ & $0.01 \pm 0.00$ & $0.02 \pm 0.00$ \\
\hline & Total alcohols & & & 2.96 & 7.46 & 0.34 & 0.56 & 3.75 & 5.02 & 5.37 & 6.89 \\
\hline & Amino acids & & & & & & & & & & \\
\hline 11 & 10.763 & 1307.5 & Proline (2TMS) & $0.02 \pm 0.00$ & $0.13 \pm 0.01$ & $0.04 \pm 0.03$ & $0.01 \pm 0.00$ & - & - & $0.19 \pm 0.06$ & $0.07 \pm 0.01$ \\
\hline 12 & 12.649 & 1434.9 & Alanine (3TMS) & $0.02 \pm 0.01$ & $0.04 \pm 0.00$ & - & - & $0.04 \pm 0.00$ & $0.06 \pm 0.01$ & - & $0.01 \pm 0.00$ \\
\hline 13 & 14.009 & 1537.2 & Pyroglutamic acid (2TMS) & $0.06 \pm 0.03$ & $0.17 \pm 0.01$ & $0.01 \pm 0.01$ & $0.06 \pm 0.01$ & $0.15 \pm 0.02$ & $0.46 \pm 0.06$ & $0.34 \pm 0.09$ & $0.51 \pm 0.05$ \\
\hline \multirow[t]{2}{*}{14} & 15.183 & 1629.1 & Glutamic acid (3TMS) & $0.02 \pm 0.01$ & $0.06 \pm 0.00$ & 年 & - & $0.01 \pm 0.00$ & - & $0.01 \pm 0.00$ & $0.01 \pm 0.00$ \\
\hline & Esters & & & & & & & & & & \\
\hline 15 & 11.590 & 1361.3 & $n$-Butylcaprylate & $2.90 \pm 0.61$ & $3.61 \pm 0.22$ & $0.01 \pm 0.00$ & $0.02 \pm 0.00$ & $4.43 \pm 0.58$ & $6.47 \pm 0.34$ & $0.01 \pm 0.00$ & $0.03 \pm 0.01$ \\
\hline 16 & 24.625 & 2600.2 & 1-Monopalmitin (2TMS) & $0.71 \pm 0.04$ & $2.08 \pm 0.27$ & $0.08 \pm 0.04$ & $0.06 \pm 0.01$ & $0.72 \pm 0.05$ & $1.76 \pm 0.31$ & $0.05 \pm 0.01$ & $0.09 \pm 0.01$ \\
\hline 17 & 25.942 & 2767 & 1-Monooleoylglycerol (2TMS) & $0.03 \pm 0.00$ & $0.42 \pm 0.02$ & $0.13 \pm 0.05$ & $0.17 \pm 0.01$ & $0.06 \pm 0.01$ & $0.11 \pm 0.01$ & $0.14 \pm 0.02$ & $0.29 \pm 0.03$ \\
\hline \multirow[t]{3}{*}{18} & 26.096 & 2777 & Glycerol monostearate (2TMS) & $11.73 \pm 2.67$ & $7.20 \pm 0.76$ & $0.37 \pm 0.28$ & $0.08 \pm 0.01$ & $3.76 \pm 0.86$ & $7.29 \pm 1.22$ & $0.02 \pm 0.01$ & $0.05 \pm 0.01$ \\
\hline & Total esters & & & 15.37 & 13.30 & 0.58 & 0.33 & 8.96 & 15.62 & 0.22 & 0.45 \\
\hline & Fatty acids & & & & & & & & & & \\
\hline 19 & 17.731 & 1848.8 & Myristic acid (TMS) & $0.02 \pm 0.00$ & $0.07 \pm 0.01$ & $0.01 \pm 0.01$ & $0.02 \pm 0.00$ & $0.04 \pm 0.00$ & $0.07 \pm 0.01$ & $0.02 \pm 0.01$ & $0.03 \pm 0.01$ \\
\hline 20 & 19.773 & 2045.7 & Palmitic acid (TMS) & $0.63 \pm 0.09$ & $2.03 \pm 0.18$ & $1.02 \pm 0.84$ & $0.49 \pm 0.09$ & $0.80 \pm 0.04$ & $1.19 \pm 0.11$ & $0.88 \pm 0.18$ & $1.36 \pm 0.12$ \\
\hline 21 & 20.737 & 2144.6 & Margaric acid (TMS) & $0.01 \pm 0.00$ & $0.04 \pm 0.01$ & $0.01 \pm 0.00$ & $0.02 \pm 0.00$ & $0.01 \pm 0.00$ & $0.02 \pm 0.00$ & $0.01 \pm 0.00$ & $0.03 \pm 0.01$ \\
\hline 22 & 21.405 & 2215.3 & Linoleic acid (TMS) & $0.21 \pm 0.00$ & $2.87 \pm 0.18$ & $0.38 \pm 0.19$ & $0.34 \pm 0.03$ & $0.55 \pm 0.06$ & $0.60 \pm 0.06$ & $1.13 \pm 0.20$ & $1.86 \pm 0.16$ \\
\hline 23 & 21.432 & 2219.3 & Oleic acid (TMS) & $0.62 \pm 0.02$ & $4.78 \pm 0.90$ & $1.73 \pm 1.22$ & $1.27 \pm 0.06$ & $1.34 \pm 0.01$ & $1.80 \pm 0.21$ & $2.29 \pm 0.17$ & $4.18 \pm 0.53$ \\
\hline 24 & 21.649 & 2242.8 & Stearic acid (TMS) & $0.54 \pm 0.04$ & $1.28 \pm 0.12$ & $0.69 \pm 0.52$ & $0.34 \pm 0.07$ & $0.77 \pm 0.04$ & $1.17 \pm 0.11$ & $0.24 \pm 0.03$ & $0.55 \pm 0.13$ \\
\hline 25 & 22.670 & 2357 & $\alpha$-Linolenic acid (TMS) & $0.04 \pm 0.00$ & $4.11 \pm 0.10$ & $0.10 \pm 0.02$ & $0.05 \pm 0.02$ & $0.02 \pm 0.00$ & $0.02 \pm 0.00$ & $0.09 \pm 0.01$ & $0.14 \pm 0.01$ \\
\hline \multirow[t]{2}{*}{26} & 23.378 & 2441.3 & Arachidic acid (TMS) & $0.01 \pm 0.00$ & $0.08 \pm 0.01$ & $0.07 \pm 0.05$ & $0.04 \pm 0.01$ & $0.02 \pm 0.00$ & $0.03 \pm 0.01$ & $0.04 \pm 0.01$ & $0.08 \pm 0.02$ \\
\hline & Total fatty acids & & & 2.08 & 15.26 & 4.01 & 2.55 & 3.55 & 4.90 & 4.70 & 8.22 \\
\hline & Inorganic acids & & & & & & & & & & \\
\hline 27 & 10.454 & 1286.7 & Phosphoric acid (3TMS) & $0.28 \pm 0.33$ & $0.28 \pm 0.08$ & $0.02 \pm 0.01$ & $0.16 \pm 0.01$ & $1.80 \pm 0.16$ & $3.35 \pm 0.40$ & $2.94 \pm 0.63$ & $3.59 \pm 1.67$ \\
\hline
\end{tabular}


Table 2. Cont.

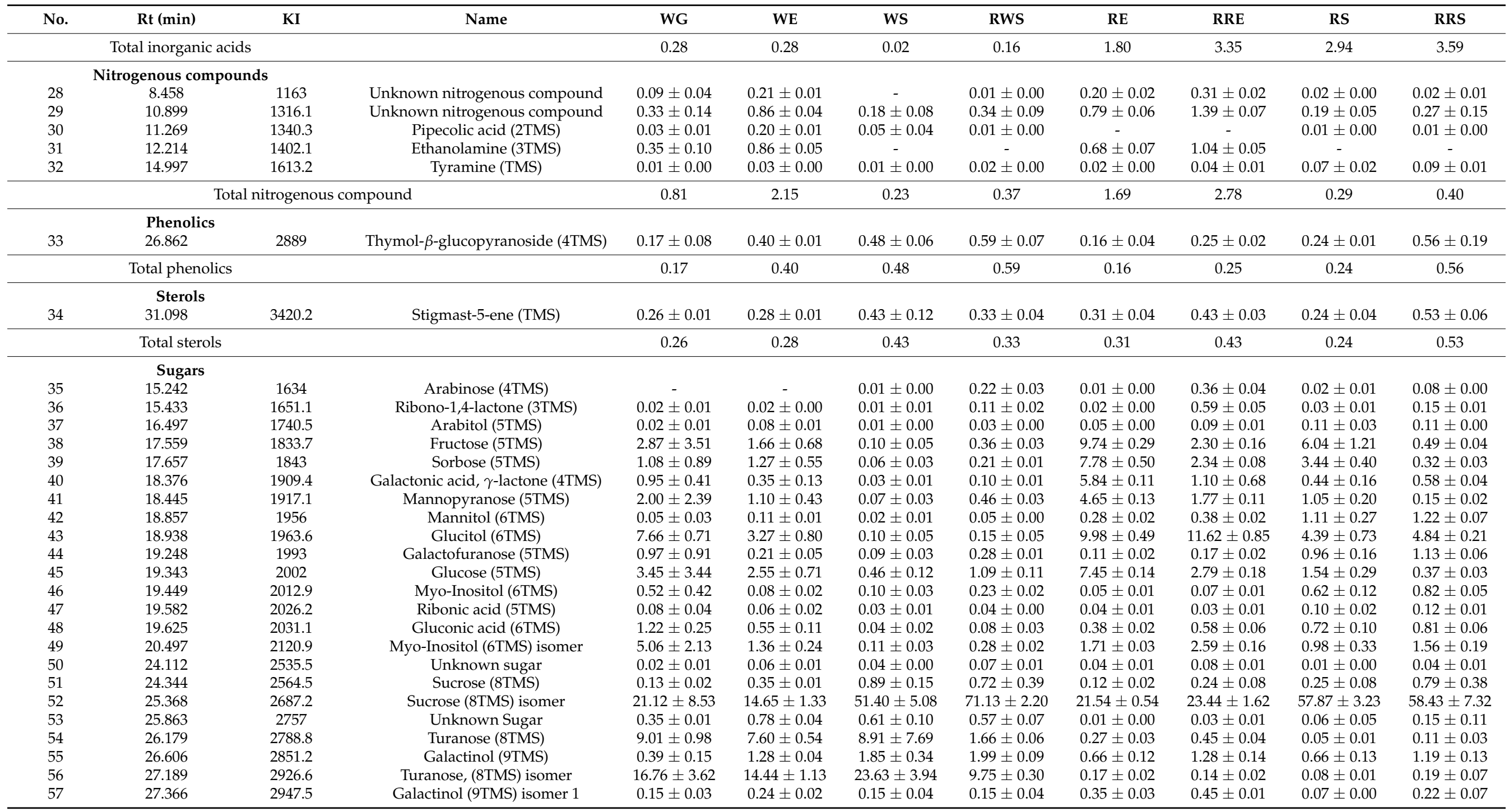


Table 2. Cont.

\begin{tabular}{|c|c|c|c|c|c|c|c|c|c|c|c|}
\hline No. & Rt (min) & KI & Name & WG & WE & WS & RWS & RE & RRE & RS & RRS \\
\hline 58 & 27.486 & 2962.8 & Melibiose (8TMS) & $0.52 \pm 0.21$ & $1.52 \pm 0.09$ & $3.30 \pm 1.14$ & $2.38 \pm 0.06$ & $0.73 \pm 0.17$ & $1.34 \pm 0.16$ & $0.90 \pm 0.23$ & $1.29 \pm 0.18$ \\
\hline 59 & 27.856 & 3009.6 & Trehalose (7TMS) & $1.84 \pm 0.17$ & $2.33 \pm 0.14$ & $0.63 \pm 0.18$ & $1.12 \pm 0.14$ & $0.03 \pm 0.00$ & $0.04 \pm 0.00$ & $0.05 \pm 0.01$ & $0.13 \pm 0.01$ \\
\hline 60 & 27.960 & 3022.7 & Galactinol (9TMS) isomer 2 & $0.62 \pm 0.15$ & $2.32 \pm 0.07$ & $0.52 \pm 0.12$ & $0.57 \pm 0.04$ & $1.26 \pm 0.24$ & $2.44 \pm 0.27$ & $0.20 \pm 0.02$ & $0.49 \pm 0.10$ \\
\hline 61 & 28.885 & 3139.7 & Unknown Sugar & $0.03 \pm 0.00$ & $0.15 \pm 0.01$ & $0.08 \pm 0.02$ & $0.10 \pm 0.02$ & $0.04 \pm 0.01$ & $0.08 \pm 0.01$ & $0.04 \pm 0.01$ & $0.07 \pm 0.01$ \\
\hline 63 & 31.202 & 3433 & Cellobiose (8TMS) & $0.02 \pm 0.00$ & $0.07 \pm 0.01$ & $0.05 \pm 0.01$ & $0.06 \pm 0.01$ & $0.09 \pm 0.03$ & $0.19 \pm 0.03$ & $0.47 \pm 0.10$ & $0.78 \pm 0.11$ \\
\hline \multirow[t]{2}{*}{64} & 31.567 & 3479.5 & Cellobiose (8TMS) isomer & $0.01 \pm 0.00$ & $0.03 \pm 0.00$ & $0.02 \pm 0.00$ & $0.03 \pm 0.01$ & $0.22 \pm 0.02$ & $0.39 \pm 0.03$ & $0.17 \pm 0.03$ & $0.28 \pm 0.03$ \\
\hline & \multicolumn{2}{|c|}{ Total sugars } & & 76.96 & 58.63 & 93.38 & 94.05 & 73.65 & 57.44 & 82.51 & 77.05 \\
\hline \multirow[t]{2}{*}{65} & $\begin{array}{c}\text { TocSophe } \\
27.787\end{array}$ & 3001.1 & $\alpha$-Tocopherol (TMS) & $0.12 \pm 0.01$ & $0.26 \pm 0.02$ & $0.28 \pm 0.03$ & $0.03 \pm 0.00$ & $0.05 \pm 0.01$ & $0.01 \pm 0.00$ & $0.10 \pm 0.03$ & $0.20 \pm 0.05$ \\
\hline & Total tocop & & & 0.12 & 0.26 & 0.28 & 0.03 & 0.05 & 0.01 & 0.10 & 0.20 \\
\hline
\end{tabular}

$\mathrm{KI}=$ Kovats index, $\mathrm{Rt}=$ retention time 
(a)

Fatty acids

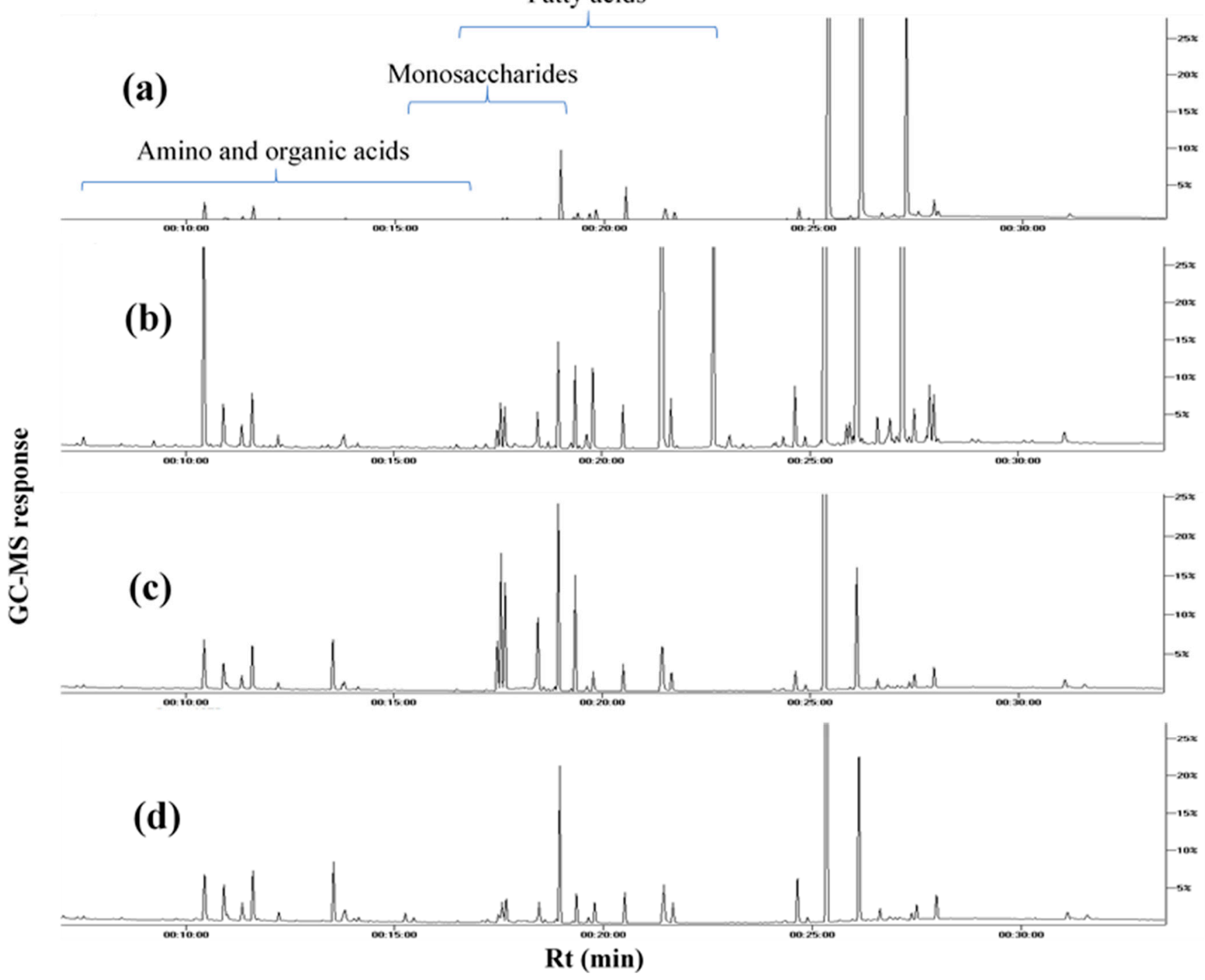

Figure 1. Representative GC-MS chromatograms of TMS derivatives of primary metabolites, collected from the extracts of (a) white mahlab from Greece "WG", (b) white mahlab from Egypt "WE", (c) red mahlab from Egypt "RE" and (d) roasted red mahlab from Egypt "RRE”.

\subsubsection{Sugars}

Sugars, mostly represented by di-saccharides, were the most dominant primary metabolite class at levels ranging from 57.4 to $94.1 \%$, comprising 30 peaks for 24 different sugars. Sucrose (peaks 51 and 52) was the main sugar detected in all samples, except for unroasted white mahlab from Egypt "WE" and Greece "WG", as turanose (peaks 54 and 56) was the predominant sugar. White mahlab and red mahlab from Sudan, "WS" and "RS", along with their roasted seeds, "RWS" and "RRS", were characterized by an abundance of sucrose at $52.3-71.9 \%$, compared to $15-23.7 \%$ in other samples. Turanose, a non-cariogenic isomer of sucrose, is present naturally in honey and exhibits a $50 \%$ sweetness level compared to that of sucrose [13]. Turanose abundance presents added value, being of low-glycemic response, and it has potential as a promising functional sweetener for controlling obesity [14]. Turanose was detected in all white mahlab seeds (11.4-32.6\%) at much higher levels than in the red ones $(0.1-0.6 \%)$, suggesting that it can function as a marker to distinguish between cultivars. Trehalose (peak 59) and cellobiose (peaks 63 and 64) content showed variation according to cultivar type or seed color. Monosaccharides in 
unroasted red mahlab from Egypt, "RE", were the major sugars detected, at 29.7\%, while the lowest level of monosaccharides was found in unroasted WS (0.8\%). A significant decrease in monosaccharide levels was observed in both roasted RRE samples from Egypt and RRS from Sudan, dropping to $9.7 \%$ and $2.5 \%$, respectively, likely due to the sugars utilization to generate Maillard products, which greatly influence seed color and flavor [15]. Major monosaccharides were fructose (peak 38), sorbose (peak 39) and glucose (peak 45) reaching 9.7, 7.8 and 7.5\%, respectively, in RE.

Having higher thermal stability, sugar alcohols do not take part in any Maillard reaction and are regarded as low-glycemic-index sweeteners compared to free sugars [16]. Roasting increased sugar alcohols, with RRE appearing to be the most enriched, at 18.9\%, followed by $14.4 \%$ for WG. Glucitol (peak 43) represented the major sugar alcohol in all specimens, except for WE, WS and RWS samples, which encompassed galactinol (peaks $55,57,60$ ) as the most abundant sugar alcohol. Myo-Inositol (peaks 46 and 49), the most abundant inositol isomer in cereals, nuts, beans and fruits, improves insulin sensitivity [17]. Whether mahlab seed could represent a potential functional food for diabetic patients needs to be now investigated based on these results. Unroasted WE from Egypt has the best sugar profile owing to the presence of reduced levels of sucrose (15\%).

\subsubsection{Organic Acids/Alcohols}

Organic acids can enhance the digestive process and, alongside their salts, boost the utilization of protein in animals, besides their preservative action in food [18]. The higher levels of organic acids in unroasted RE and roasted red mahlab, "RRE", from Egypt (5.9$9.7 \%)$, with an abundance of malic acid (4.7-7.4\%), account for their sour taste compared to other samples. Succinic (peak 4), $\gamma$-hydroxybutyric (peak 3), oxalic (peak 2) and glycolic (peak 1) acids were also present in all mahlab samples. Malic acid (peak 5), a common acid in unripe fruit, is used to enhance beverages as a food acidulant [19]. $\gamma$-Hydroxybutyric acid, a natural neurotransmitter in the mammalian brain, is used therapeutically to treat alcoholism and narcolepsy [20].

It is noteworthy to mention that phytic acid, an anti-nutrient that interferes with the bioavailability of proteins and minerals owing to its strong chelating property, was absent from all seeds, indicating their good food quality [10].

Glycerol (0.3-7.4\%) and glycerol-3-phosphate (peak 10) were identified as alcohols in all mahlab seeds except WG and RE. Although glycerol (peak 9) has a role in Maillard reactions as an active flavor precursor during roasting, its level interestingly showed an increase post-roasting, likely due to the increased lipid degradation [21].

\subsubsection{Amino Acids/Nitrogenous Compounds}

Low amino acid levels at $0.05-0.60 \%$ in mahlab seeds were detected, represented by proline (peak 11), alanine (peak 12), pyroglutamic (peak 13) and glutamic (peak 14) acids. Mahlab seeds from Egypt, "WE", "RE" and "RRE", were the most enriched in $\beta$-ethanolamine (peak 31), an amino alcohol.

\subsubsection{Fatty Acids/Acyl Esters/Sterols}

Another considerable metabolite class present in all examined seeds was fatty acids, reaching $15.3 \%$ in white mahlab, "WE", from Egypt, also accounting for its fatty taste. The monounsaturated omega-9 fatty acid, oleic acid (peak 23), was most enriched in WE $(4.8 \%)$, making it the major fatty acid, indicating a heart-healthy functional food with diminished LDL (low-density lipoprotein) cholesterol [22]. An oleic-acid-rich diet has been reported to reduce the risk of atherosclerosis and type 2 diabetes [23]. The essential omega- 3 polyunsaturated $\alpha$-linolenic fatty acid (peak 25), detected at the highest levels in WE (4.1\%), exhibits neuroprotective, anti-inflammatory, antioxidant and antidepressant effects [24]. White mahlab, "WE", showed the highest omega 3/6 ratio among all seed accessions, providing the best fatty acid profile with the highest oleic acid content. The omega $3 / 6$ ratio was observed to decline upon roasting, particularly in WS. $\alpha$-Tocopherol (peak 65), 
a major constituent of vitamin $\mathrm{E}$ with a protective effect against atherosclerosis [25], and stigmast-5-ene were further detected in all mahlab seeds though at trace levels.

With regard to fatty acyl esters, the highest levels were detected in mahlab from Egypt, "WE", "RE" and "RRE", and Greece, "WG" (9-15.6\%), with glycerol monostearate (peak 18) and n-butylcaprylate (peak 15 ) as major esters compared to $0.2-0.6 \%$ only in samples from Sudan. Glycerol monostearate is an anti-staling additive for bakery products that is widely used to improve the appearance and taste of flour foods and its abundance can account for the common use of mahlab seeds in bakery, aside from its role as flavor enhancer [26]. Generally, monoglycerides act as emulsifiers, yielding a more stable air-dispersed baked cake with a fairly soft crumb [27]. Another acyl ester of potential flavor described as fruity is n-butylcaprylate, detected at maximal levels in roasted red mahlab, "RRE" (6.5\%), which is used in various foodstuffs, further rationalizing how roasting improves mahlab flavor [28].

\subsubsection{Inorganic Acids}

Phosphoric acid (peak 27) was the only inorganic acid detected in higher levels in red mahlab seeds $(1.8-3.6 \%)$ versus white types at $0.02-0.28 \%$, suggesting that it can function as a marker to distinguish between mahlab cultivars of different colors. Phosphoric acid improves the antioxidant activity of $\alpha$-tocopherol, aside from being a food preservative [29].

\subsubsection{Phenolics}

The only identified phenolic compound was thymol- $\beta$-glucopyranoside (peak 33), which could serve as a precursor for thymol, the principal flavoring in mahlab. Many flavor and aroma components are bound to sugars in the form of glycosides. Glycosidically bound volatile compounds in plants are predominantly $O-\beta$-D-glucosides and $O$-diglycosides [30]. As most of the free forms consist of compounds with interesting flavor properties, their glycosides, acting as important potential aroma reserves, are usually greater than their free volatile counterparts. The odorous aglycones are released from precursors during various processing steps by enzymatic and non-enzymatic transformations [31].

\subsection{HCA and PCA Analysis of Primary Metabolome of Unroasted White and Red Mahlab Seeds}

Multivariate data analyses were conducted in order to better assess the primary metabolite heterogeneity among mahlab specimens in an unbiased manner using HCA and PCA. HCA acquired a dendrogram of three distinct clusters (Figure 2a), where white mahlab specimens from Egypt, "WE", clustered in group 1, while other samples from Egypt, in addition to all seeds from Sudan and Greece, were separated into two subdivisions from group 2. However, the clustering of raw and roasted samples together in group 2 indicates that HCA failed to characterize the impact of roasting on mahlab seeds based on their silylated primary metabolite content. A PCA model (Figure $2 b$ ) was illustrated by two orthogonal PCs, justifying $72 \%$ of the entire variance, with the obvious discrimination of all mahlab seeds from Egypt at the right side of PC1, whereas RWS, RS and RRS were segregated in one intermixed cluster on the left side of PC1. Inspection of the loading plot in Figure 2c indicates that higher fatty acid levels were in agreement with the enriched content of oleic (peak 23) and $\alpha$-linolenic (peak 25) acids in addition to glycerol (peak 9) in white mahlab seeds, also explaining its segregation on the lower right side of the loading plot. Moreover, WE seeds showed the highest content in lactones in the GC-MS analysis of volatiles, indicating a positive relationship between fatty acids and lactones. Roasted red mahlab seed "RRE" was characterized by high levels of $n$-butylcaprylate (peak 15) versus glucose (peak 25) abundance in unroasted RE seeds, likely be consumed in the Maillard reaction partially upon roasting. In contrast, glycerol monostearate (peak 18) was the dominant ester in white mahlab, "WG", from Greece. 


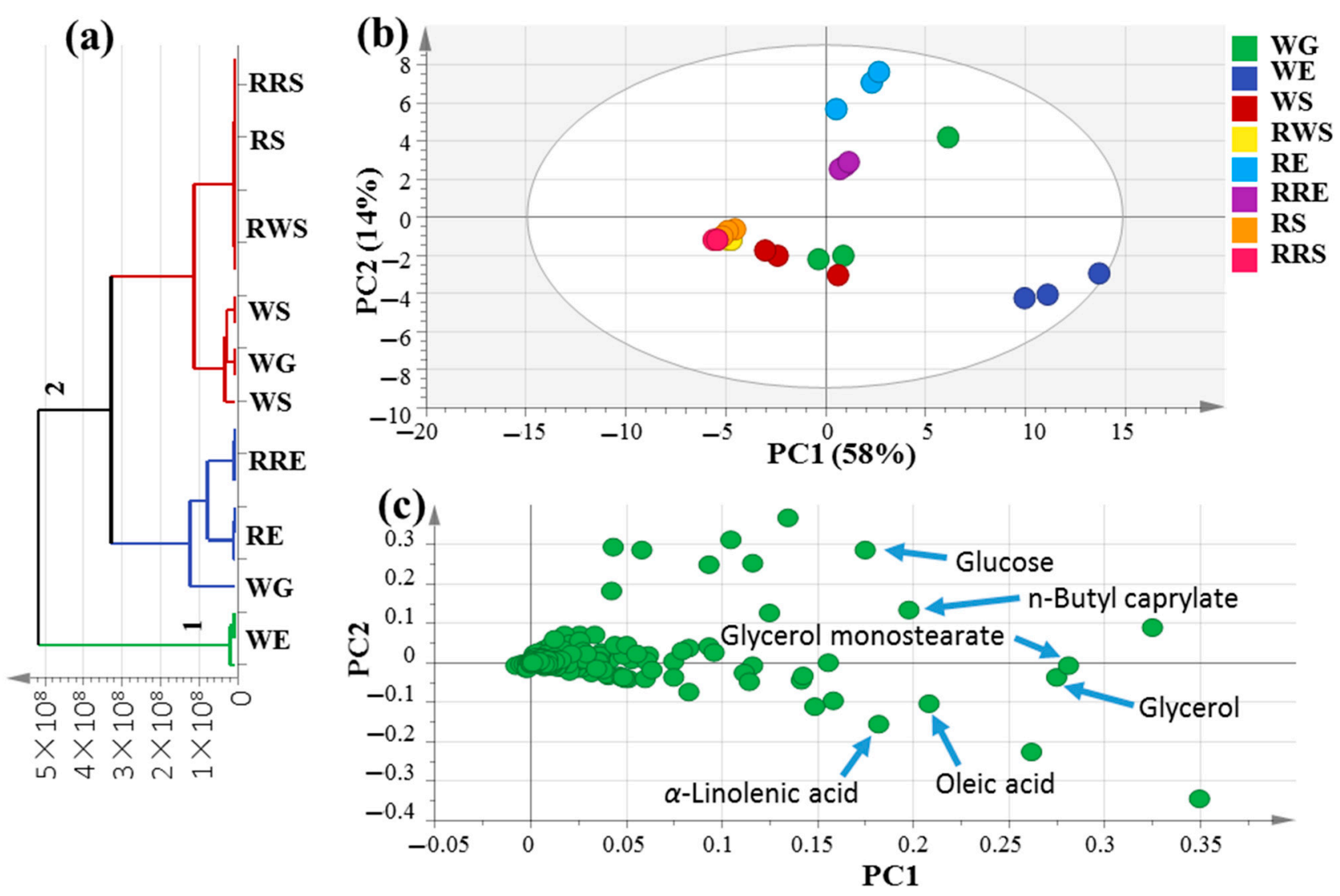

Figure 2. Unsupervised multivariate data analyses of the studied $P$. mahaleb seeds derived from modeling silylated primary metabolites analyzed via GC-MS $(n=3)$. (a) HCA plot. (b) PCA score plot of PC1 vs. PC2 scores. (c) The respective loading plot for PC1 and PC2, providing mass peaks and their assignments. The metabolome clusters are placed in two-dimensional space at the distinct locations defined by two vectors of principal component PC $1=58 \%$ and PC2 $=14 \%$.

\subsection{OPLS-DA Analysis of Unroasted White and Red Mahlab Seeds}

The supervised orthogonal partial least squares discriminant analysis (OPLS-DA) score plot in Figure 3a was further employed to assess mahlab seed classification based on its cultivar type, which failed to separate in PCA analysis, by constructing a model of raw white "WG", "WE" and "WS" against red "RE" and "RS" mahlab of different origins. OPLS-DA has a greater capability for marker recognition by supplying the most pertinent variables for the distinction of two class groups. With $\mathrm{Q} 2=0.5$ indicating the predictability of the model, the OPLS score plot demonstrated $59 \%$ of the total variance $(R 2=0.59)$. The respective loading S-plot (Figure 3b) revealed that turanose (peak 54) and its isomer (peak 56) were enriched in unroasted white mahlab compared to red ones, with $p$ value $<0.005$. 


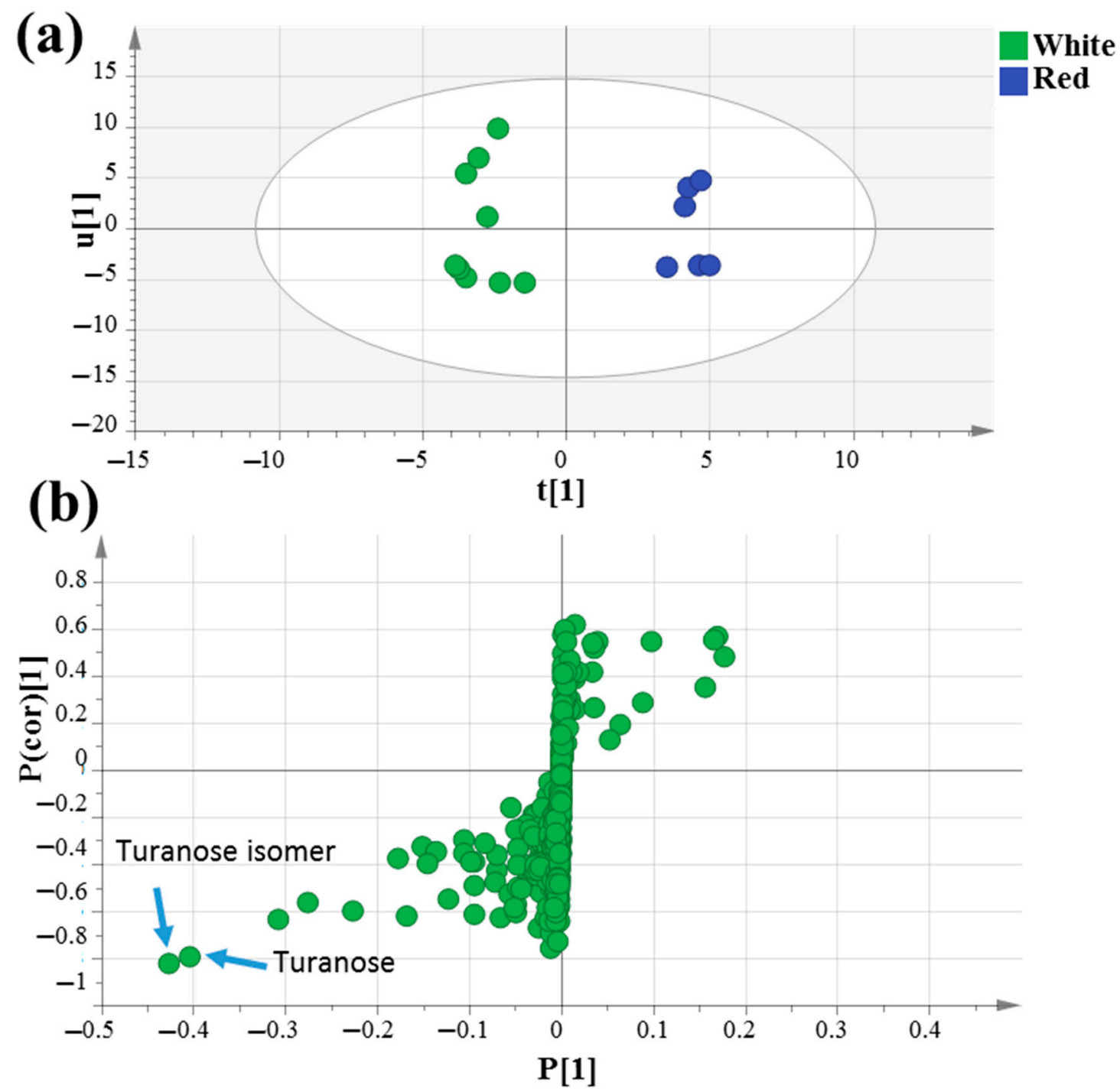

Figure 3. GC-MS-based OPLS-DA score plot (a) derived from modeling silylated primary metabolites of unroasted white versus red mahlab $(n=3)$. The respective loading S-plots $(\mathbf{b})$ showing the covariance $p$ [1] against the correlation $p$ (cor) [1] of the variables of the discriminating component of the OPLS-DA model. Cut-off values of $p<0.005$ were used. Designated variables are highlighted and identifications are discussed in the text.

\subsection{Headspace Volatile Analysis Using SPME-GC-MS of Mahlab Samples (Roasted/Unroasted)}

Some mahlab seeds (roasted and unroasted), "WG", "WE", "RE" and "RRE", were selected for volatile analysis based on their lower sugar content, as they are considered healthier foods, in addition to their higher ester levels, indicating a rich aroma. Headspacesolid-phase microextraction (HS-SPME) led to the identification of 135 volatiles belonging to several phytochemical classes, viz., organic acids, alcohols, aldehydes, esters, furans, ketones, lactones, aliphatic hydrocarbons, aromatics and sesqui- and monoterpenes (Table 3, Supplementary Figure S1). 
Table 3. Relative percentage of volatile constituents in $P$. mahaleb seeds analyzed using SPME-GC-MS, $n=3$. For codes, refer to Table 1.

\begin{tabular}{|c|c|c|c|c|c|c|c|}
\hline No. & Volatiles & KI & Rt (min) & WG & WE & RE & RRE \\
\hline & Organic and Fatty Acids & & & & & & \\
\hline 1 & Formic acid & 491.5 & 1.75 & $0.69 \pm 0.42$ & $1.01 \pm 0.28$ & $0.44 \pm 0.06$ & $1.31 \pm 0.45$ \\
\hline 2 & Acetic acid * & 530.7 & 2.118 & $1.60 \pm 0.32$ & $2.23 \pm 0.26$ & $7.18 \pm 2.21$ & $1.27 \pm 0.62$ \\
\hline 3 & Propanoic acid & 609.4 & 3.002 & $0.07 \pm 0.06$ & $0.02 \pm 0.01$ & $0.15 \pm 0.07$ & $0.04 \pm 0.03$ \\
\hline 4 & Butanoic acid & 723 & 4.189 & $0.51 \pm 0.31$ & $0.50 \pm 0.09$ & $0.14 \pm 0.08$ & $0.24 \pm 0.13$ \\
\hline 5 & Valeric acid & 873.4 & 5.796 & $9.22 \pm 1.16$ & $13.23 \pm 3.73$ & $6.09 \pm 0.62$ & $5.78 \pm 2.04$ \\
\hline 6 & Valeric acid isomer & 901.8 & 6.046 & $9.22 \pm 1.16$ & $0.14 \pm 0.12$ & $0.04 \pm 0.00$ & $0.06 \pm 0.01$ \\
\hline 7 & Caproic acid & 990.2 & 7.144 & $0.43 \pm 0.04$ & $0.24 \pm 0.10$ & $0.69 \pm 0.20$ & $0.82 \pm 0.56$ \\
\hline 8 & 3-Hexenoic acid & 1022.9 & 7.333 & $0.06 \pm 0.01$ & $0.05 \pm 0.01$ & $0.09 \pm 0.07$ & $0.18 \pm 0.05$ \\
\hline 9 & Heptanoic acid & 1081.1 & 7.967 & $0.02 \pm 0.01$ & $0.02 \pm 0.01$ & $0.04 \pm 0.01$ & $0.09 \pm 0.06$ \\
\hline 10 & 2-Ethylcaproic acid & 1115.4 & 8.36 & - & $0.01 \pm 0.00$ & $0.05 \pm 0.01$ & $0.01 \pm 0.00$ \\
\hline 11 & 2-Heptenoic acid & 1113 & 8.393 & $0.13 \pm 0.03$ & $0.14 \pm 0.02$ & $0.21 \pm 0.04$ & $1.02 \pm 0.74$ \\
\hline 12 & Caprylic acid & 1168 & 9.036 & $0.02 \pm 0.00$ & $0.02 \pm 0.00$ & $0.01 \pm 0.00$ & $0.63 \pm 0.12$ \\
\hline 13 & 2-Octenoic acid & 1205.2 & 9.275 & $0.13 \pm 0.08$ & $0.14 \pm 0.03$ & $0.35 \pm 0.29$ & $0.04 \pm 0.03$ \\
\hline 14 & Nonanoic acid & 1267.7 & 9.911 & $0.01 \pm 0.00$ & $0.09 \pm 0.03$ & $0.21 \pm 0.11$ & $0.02 \pm 0.00$ \\
\hline 15 & Nonanoic acid isomer & 1273 & 9.987 & $0.14 \pm 0.03$ & $0.43 \pm 0.08$ & $0.25 \pm 0.02$ & $1.10 \pm 0.21$ \\
\hline 16 & Capric acid & 1347.8 & 10.686 & $0.04 \pm 0.02$ & $0.06 \pm 0.00$ & $0.06 \pm 0.01$ & $0.06 \pm 0.00$ \\
\hline 17 & Myristic acid & 1759 & 14.679 & $0.02 \pm 0.01$ & $0.13 \pm 0.09$ & $0.22 \pm 0.14$ & $0.05 \pm 0.02$ \\
\hline 18 & Pentadecanoic acid & 1848.8 & 15.6 & $0.04 \pm 0.03$ & $0.03 \pm 0.02$ & $0.07 \pm 0.09$ & $0.39 \pm 0.55$ \\
\hline 19 & Palmitoleic acid & 1929.3 & 16.285 & $0.02 \pm 0.01$ & $0.09 \pm 0.06$ & $0.16 \pm 0.13$ & $0.03 \pm 0.02$ \\
\hline \multirow[t]{3}{*}{20} & Palmitic acid & 1949.3 & 16.481 & $0.11 \pm 0.03$ & $0.54 \pm 0.37$ & $0.96 \pm 0.65$ & $0.24 \pm 0.10$ \\
\hline & Total acids & & & 22.47 & 19.12 & 17.43 & 13.37 \\
\hline & Alcohols & & & & & & \\
\hline 21 & 1-Butanol & 584.9 & 2.71 & $0.99 \pm 0.57$ & $0.04 \pm 0.02$ & $0.10 \pm 0.03$ & $0.02 \pm 0.01$ \\
\hline 22 & 1-Pentanol (amyl alcohol) & 704.8 & 4.021 & $1.91 \pm 0.74$ & $0.15 \pm 0.07$ & $0.52 \pm 0.26$ & $0.16 \pm 0.07$ \\
\hline 23 & 2,3-Butanediol & 721.2 & 4.167 & $0.12 \pm 0.02$ & $0.25 \pm 0.19$ & $0.98 \pm 0.65$ & $0.11 \pm 0.08$ \\
\hline 24 & 2,3-Butanediol isomer & 734.3 & 4.241 & $0.12 \pm 0.02$ & $0.25 \pm 0.19$ & $0.96 \pm 0.66$ & $0.18 \pm 0.08$ \\
\hline 25 & 1-Hexanol* & 837.7 & 5.401 & $0.47 \pm 0.11$ & $0.15 \pm 0.11$ & $1.45 \pm 0.55$ & $0.07 \pm 0.02$ \\
\hline 26 & 1-Heptanol & 960.7 & 6.725 & $0.36 \pm 0.06$ & $0.22 \pm 0.11$ & $0.50 \pm 0.19$ & $0.71 \pm 0.25$ \\
\hline 27 & 3-Octenol & 972.3 & 6.847 & $1.37 \pm 0.24$ & $1.07 \pm 0.33$ & $1.62 \pm 0.81$ & $0.97 \pm 0.37$ \\
\hline \multirow[t]{3}{*}{28} & 1-Octanol & 1072.2 & 7.933 & $0.58 \pm 0.10$ & $0.91 \pm 0.33$ & $0.61 \pm 0.13$ & $3.20 \pm 0.88$ \\
\hline & Total alcohols & & & 5.93 & 3.05 & 6.75 & 5.44 \\
\hline & Aldehydes & & & & & & \\
\hline 29 & Valeraldehyde & 619.4 & 3.114 & $8.08 \pm 3.24$ & $0.51 \pm 0.17$ & $0.77 \pm 0.31$ & $0.29 \pm 0.15$ \\
\hline 30 & 2-Pentenal & 691.7 & 3.847 & $0.02 \pm 0.01$ & $0.02 \pm 0.01$ & $0.02 \pm 0.01$ & $0.01 \pm 0.00$ \\
\hline 31 & Caproaldehyde (Hexanal) & 748.1 & 4.47 & $7.07 \pm 2.20$ & $0.36 \pm 0.10$ & $1.32 \pm 0.51$ & $0.80 \pm 0.49$ \\
\hline 32 & Nonanal * & 817.3 & 5.221 & $0.12 \pm 0.02$ & $0.04 \pm 0.02$ & $0.11 \pm 0.02$ & $0.19 \pm 0.23$ \\
\hline 33 & Heptanal * & 880 & 5.869 & $0.94 \pm 0.15$ & $2.44 \pm 3.34$ & $0.13 \pm 0.02$ & $0.72 \pm 0.83$ \\
\hline 34 & 2,4-Heptadienal & 916.7 & 6.243 & $0.28 \pm 0.01$ & $0.05 \pm 0.02$ & $0.10 \pm 0.01$ & $0.02 \pm 0.01$ \\
\hline 35 & 2-Heptenal & 947.3 & 6.574 & $0.66 \pm 0.09$ & $0.18 \pm 0.05$ & $0.51 \pm 0.02$ & $0.09 \pm 0.03$ \\
\hline 36 & Benzaldehyde * & 955.4 & 6.658 & $0.88 \pm 0.03$ & $2.60 \pm 0.94$ & $18.71 \pm 6.63$ & $0.87 \pm 0.61$ \\
\hline 37 & Octanal & 1001 & 7.192 & $0.07 \pm 0.05$ & $0.03 \pm 0.01$ & $0.06 \pm 0.05$ & $0.40 \pm 0.24$ \\
\hline 38 & Phenylacetaldehyde * & 1049.9 & 7.668 & $0.06 \pm 0.03$ & $0.04 \pm 0.01$ & $0.20 \pm 0.05$ & $0.03 \pm 0.01$ \\
\hline 39 & 2-Octenal & 1061.4 & 7.785 & $1.05 \pm 0.13$ & $0.68 \pm 0.24$ & $1.52 \pm 0.18$ & $0.93 \pm 0.36$ \\
\hline 40 & Nonanal isomer & 1108.7 & 8.302 & $1.48 \pm 0.10$ & $2.05 \pm 0.90$ & $3.24 \pm 0.80$ & $5.50 \pm 2.54$ \\
\hline 41 & 2,4-Octadienal & 1115.8 & 8.402 & $0.01 \pm 0.00$ & $0.02 \pm 0.03$ & $0.02 \pm 0.01$ & $0.01 \pm 0.00$ \\
\hline 42 & Decanal * & 1123 & 8.448 & $0.02 \pm 0.00$ & $0.17 \pm 0.04$ & $1.16 \pm 0.04$ & $0.10 \pm 0.01$ \\
\hline 43 & 2,4-Nonadienal & 1133.4 & 8.661 & $0.05 \pm 0.00$ & $0.09 \pm 0.02$ & $0.11 \pm 0.02$ & $0.15 \pm 0.01$ \\
\hline 44 & 2-Nonenal & 1165.1 & 8.893 & $0.07 \pm 0.01$ & $0.10 \pm 0.02$ & $0.19 \pm 0.12$ & $0.13 \pm 0.02$ \\
\hline 45 & 2-Propyl-2-heptenal & 1190.9 & 9.176 & $0.24 \pm 0.03$ & $0.05 \pm 0.01$ & $0.14 \pm 0.01$ & $0.01 \pm 0.00$ \\
\hline 46 & 2,4 -Nonadienal isomer & 1198.9 & 9.264 & $0.49 \pm 0.16$ & $0.82 \pm 0.11$ & $0.85 \pm 0.01$ & $0.19 \pm 0.05$ \\
\hline 47 & Cinnamaldehyde * & 1222.3 & 9.471 & $7.25 \pm 2.45$ & $12.31 \pm 1.67$ & $11.19 \pm 0.52$ & $1.96 \pm 0.34$ \\
\hline 48 & 4,5-Epoxy-2-decenal & 1235.8 & 9.658 & $0.01 \pm 0.00$ & $0.01 \pm 0.00$ & $0.03 \pm 0.02$ & $0.38 \pm 0.53$ \\
\hline 49 & 4-Oxononanal & 1252.4 & 9.746 & $1.74 \pm 0.44$ & $3.95 \pm 0.39$ & $0.72 \pm 0.07$ & $1.96 \pm 0.41$ \\
\hline 50 & Cuminaldehyde * & 1255.4 & 9.819 & $0.01 \pm 0.00$ & $0.24 \pm 0.03$ & $1.50 \pm 0.39$ & $0.04 \pm 0.00$ \\
\hline 51 & 2-Decenal & 1268.8 & 9.917 & $0.62 \pm 0.06$ & $1.00 \pm 0.31$ & $0.29 \pm 0.07$ & $3.64 \pm 0.64$ \\
\hline 52 & Cinnamaldehyde isomer & 1285.4 & 10.078 & $4.88 \pm 1.60$ & $3.84 \pm 1.29$ & $0.21 \pm 0.03$ & $0.12 \pm 0.01$ \\
\hline 53 & 2-Hydroxy-p-anisaldehyde & 1345.3 & 10.668 & $0.32 \pm 0.16$ & $0.42 \pm 0.21$ & $0.09 \pm 0.07$ & $0.04 \pm 0.01$ \\
\hline 54 & Piperonal & 1350.9 & 10.694 & $0.72 \pm 0.63$ & $0.34 \pm 0.18$ & $1.13 \pm 0.39$ & $0.54 \pm 0.46$ \\
\hline 55 & 2-Undecenal & 1369.7 & 10.758 & $0.03 \pm 0.02$ & $0.05 \pm 0.01$ & $0.09 \pm 0.03$ & $0.21 \pm 0.16$ \\
\hline 56 & Dodecanal & 1396.4 & 11.232 & $0.15 \pm 0.07$ & $0.07 \pm 0.01$ & $0.13 \pm 0.02$ & $0.11 \pm 0.09$ \\
\hline \multirow[t]{2}{*}{57} & Isovanillin (3-Hydroxy-p-anisaldehyde) & 1409.3 & 11.256 & $0.02 \pm 0.01$ & $0.04 \pm 0.01$ & $0.07 \pm 0.02$ & $0.06 \pm 0.05$ \\
\hline & Total aldehydes & & & 37.34 & 32.52 & 44.60 & 19.48 \\
\hline & Aliphatic hydrocarbons & & & & & & \\
\hline 58 & Dodecane & 1112.9 & 8.341 & $0.17 \pm 0.00$ & $0.19 \pm 0.01$ & $0.08 \pm 0.00$ & $0.44 \pm 0.06$ \\
\hline
\end{tabular}


Table 3. Cont.

\begin{tabular}{|c|c|c|c|c|c|c|c|}
\hline No. & Volatiles & KI & Rt (min) & WG & WE & RE & RRE \\
\hline 59 & Pentadecane & 1482.7 & 11.96 & $0.05 \pm 0.03$ & $0.10 \pm 0.02$ & $0.01 \pm 0.00$ & $0.10 \pm 0.00$ \\
\hline 60 & 2,2,4,6,6-Pentamethylheptane & 1023.9 & 7.355 & $0.01 \pm 0.00$ & $0.01 \pm 0.01$ & $0.01 \pm 0.00$ & $0.01 \pm 0.00$ \\
\hline 61 & 2,2,7,7-Tetramethyloctane & 1031.8 & 7.492 & $0.07 \pm 0.01$ & $0.04 \pm 0.01$ & $0.11 \pm 0.02$ & $0.03 \pm 0.02$ \\
\hline 62 & Tetradecane * & 1384.9 & 11.028 & $0.16 \pm 0.07$ & $0.13 \pm 0.05$ & $0.04 \pm 0.01$ & $0.04 \pm 0.00$ \\
\hline 63 & Hexadecane * & 1599 & 13.199 & $0.01 \pm 0.00$ & $0.18 \pm 0.06$ & $0.23 \pm 0.06$ & $0.14 \pm 0.13$ \\
\hline 64 & Heptadecane * & 1709.8 & 14.229 & $0.00 \pm 0.01$ & $0.02 \pm 0.02$ & $0.02 \pm 0.01$ & $0.12 \pm 0.14$ \\
\hline 65 & Octadecane * & 1797.4 & 15.003 & - & - & - & $0.04 \pm 0.05$ \\
\hline \multirow[t]{3}{*}{66} & Nonadecane * & 1888.9 & 16.022 & - & - & - & $0.01 \pm 0.01$ \\
\hline & Total aliphatic hydrocarbons & & & 0.48 & 0.65 & 0.50 & 0.92 \\
\hline & Aromatics & & & & & & \\
\hline 67 & Unknown & 1326.2 & 10.473 & $2.46 \pm 2.17$ & $0.97 \pm 0.54$ & $3.32 \pm 1.00$ & $8.05 \pm 8.15$ \\
\hline 68 & Naphthalene ${ }^{*}$ & 1044.1 & 7.607 & - & - & - & $2.71 \pm 3.83$ \\
\hline \multirow[t]{3}{*}{69} & Unknown & 1207.9 & 9.335 & $0.10 \pm 0.02$ & $0.10 \pm 0.03$ & $0.05 \pm 0.02$ & $0.59 \pm 0.17$ \\
\hline & Total aromatics & & & 2.56 & 1.07 & 3.37 & 11.35 \\
\hline & Esters & & & & & & \\
\hline 70 & Butyl formate & 653.4 & 3.464 & $0.15 \pm 0.07$ & $0.01 \pm 0.00$ & $0.02 \pm 0.00$ & - \\
\hline 71 & $n$-Butyl acetate & 768.2 & 4.524 & $0.87 \pm 0.28$ & $0.05 \pm 0.01$ & $0.13 \pm 0.09$ & $0.06 \pm 0.04$ \\
\hline 72 & Unknown & 775.4 & 4.77 & $0.10 \pm 0.04$ & $0.13 \pm 0.09$ & $0.33 \pm 0.11$ & $0.13 \pm 0.07$ \\
\hline 73 & $n$-Pentyl formate & 784.1 & 4.875 & $0.38 \pm 0.13$ & $0.02 \pm 0.00$ & $0.06 \pm 0.01$ & $0.01 \pm 0.00$ \\
\hline 74 & Hexyl formate & 912 & 6.205 & $0.09 \pm 0.02$ & $0.03 \pm 0.01$ & $0.06 \pm 0.01$ & $0.02 \pm 0.01$ \\
\hline 75 & Benzyl formate & 1084.6 & 8.13 & $0.03 \pm 0.00$ & $0.01 \pm 0.00$ & $0.09 \pm 0.05$ & $0.05 \pm 0.03$ \\
\hline 76 & Pentyl valerate & 1096.3 & 8.168 & $1.65 \pm 0.18$ & $0.29 \pm 0.19$ & $1.22 \pm 0.46$ & $0.41 \pm 0.42$ \\
\hline 77 & Linalyl formate & 1105 & 8.272 & $0.10 \pm 0.00$ & $0.08 \pm 0.03$ & $0.21 \pm 0.03$ & $0.07 \pm 0.01$ \\
\hline 78 & Octyl formate & 1132.3 & 8.553 & $0.12 \pm 0.01$ & $0.19 \pm 0.09$ & $0.33 \pm 0.08$ & $0.69 \pm 0.23$ \\
\hline 79 & Octyl acetate & 1137.9 & 8.678 & $0.11 \pm 0.01$ & $0.21 \pm 0.05$ & $0.28 \pm 0.03$ & $0.50 \pm 0.12$ \\
\hline 80 & Pentyl valerate isomer & 1192 & 9.193 & $1.87 \pm 0.16$ & $0.81 \pm 0.35$ & $1.62 \pm 0.30$ & $0.62 \pm 0.23$ \\
\hline 81 & Octyl acetate isomer & 1212.4 & 9.366 & $0.32 \pm 0.07$ & $0.79 \pm 0.11$ & $0.66 \pm 0.05$ & $3.26 \pm 1.28$ \\
\hline 82 & Pentyl caproate & 1292.2 & 10.152 & $0.95 \pm 0.28$ & $0.61 \pm 0.08$ & $0.41 \pm 0.02$ & $2.25 \pm 0.49$ \\
\hline 83 & $\alpha$-Terpinyl acetate * & 1332.5 & 10.546 & $0.03 \pm 0.01$ & $0.03 \pm 0.00$ & $0.09 \pm 0.03$ & $0.03 \pm 0.03$ \\
\hline 84 & Hexyl caproate & 1387.4 & 11.039 & $0.25 \pm 0.11$ & $0.24 \pm 0.03$ & $0.11 \pm 0.01$ & $0.27 \pm 0.01$ \\
\hline 85 & Benzyl valerate & 1446.3 & 11.601 & $0.04 \pm 0.02$ & $0.05 \pm 0.01$ & $0.01 \pm 0.00$ & $0.06 \pm 0.00$ \\
\hline 86 & Octyl isovalerate & 1476.2 & 11.949 & $0.06 \pm 0.03$ & $0.09 \pm 0.02$ & $0.03 \pm 0.02$ & $0.26 \pm 0.01$ \\
\hline 87 & Octyl hexanoate & 1578.7 & 13.026 & $0.01 \pm 0.00$ & $0.01 \pm 0.00$ & $0.14 \pm 0.09$ & $0.05 \pm 0.01$ \\
\hline 88 & Benzyl Benzoate * & 1783.5 & 14.903 & $0.02 \pm 0.02$ & $0.09 \pm 0.09$ & $0.09 \pm 0.00$ & $0.08 \pm 0.02$ \\
\hline \multirow[t]{3}{*}{89} & Methyl palmitate & 1915.6 & 16.137 & $0.01 \pm 0.00$ & $0.02 \pm 0.01$ & $0.05 \pm 0.03$ & $0.02 \pm 0.02$ \\
\hline & Total esters & & & 7.14 & 3.76 & 5.94 & 8.85 \\
\hline & Ethers & & & & & & \\
\hline 90 & Estragole * & 1207.4 & 9.319 & $0.01 \pm 0.00$ & $0.02 \pm 0.00$ & $0.05 \pm 0.01$ & $0.03 \pm 0.03$ \\
\hline \multirow[t]{3}{*}{91} & Eugenol * & 1342.7 & 10.584 & - & - & - & $0.08 \pm 0.12$ \\
\hline & Total ethers & & & 0.01 & 0.02 & 0.05 & 0.12 \\
\hline & Furans & & & & & & \\
\hline 92 & 2,3-Dihydrofuran & 575.1 & 2.641 & $0.06 \pm 0.01$ & $0.03 \pm 0.01$ & $0.02 \pm 0.01$ & $0.01 \pm 0.00$ \\
\hline 93 & 2-Propylfuran & 736.5 & 4.345 & $0.05 \pm 0.01$ & $0.01 \pm 0.01$ & $0.02 \pm 0.00$ & $0.01 \pm 0.00$ \\
\hline 94 & 3-Furfural * & 794 & 4.955 & $0.01 \pm 0.01$ & $0.01 \pm 0.00$ & $0.05 \pm 0.03$ & $0.01 \pm 0.01$ \\
\hline 95 & 2-Butylfuran & 868.9 & 5.737 & $1.49 \pm 0.07$ & $0.27 \pm 0.13$ & $0.49 \pm 0.12$ & $0.15 \pm 0.08$ \\
\hline 96 & 2-Pentylfuran & 988.5 & 7.012 & $2.65 \pm 0.23$ & $0.73 \pm 0.30$ & $2.73 \pm 0.71$ & $1.77 \pm 0.92$ \\
\hline 97 & 4-Methyl-2-propyl furan & 1033.9 & 7.538 & $0.18 \pm 0.03$ & $0.04 \pm 0.02$ & $0.12 \pm 0.02$ & $0.06 \pm 0.03$ \\
\hline 98 & 5-Methyl-2-propionylfuran & 1152.1 & 8.726 & $0.21 \pm 0.02$ & $0.22 \pm 0.04$ & $0.01 \pm 0.00$ & $0.06 \pm 0.02$ \\
\hline \multirow[t]{3}{*}{99} & 1-(2-Furyl)-3-butene-1,2-diol & 1174.1 & 8.959 & $0.74 \pm 0.11$ & $1.10 \pm 0.05$ & $0.39 \pm 0.04$ & $4.30 \pm 0.99$ \\
\hline & Total furans & & & 5.41 & 2.39 & 3.84 & 6.37 \\
\hline & Ketones & & & & & & \\
\hline 100 & 2-Hexanone & 735.5 & 4.327 & $0.14 \pm 0.03$ & $0.09 \pm 0.10$ & $0.95 \pm 0.53$ & $0.06 \pm 0.03$ \\
\hline 101 & 3-Methyl-1-cyclopentanone & 812.3 & 4.956 & $0.04 \pm 0.01$ & $0.05 \pm 0.03$ & $0.13 \pm 0.10$ & $0.05 \pm 0.02$ \\
\hline 102 & 3-Octen-2-one & 1040.8 & 7.568 & $2.31 \pm 0.29$ & $0.82 \pm 0.33$ & $2.88 \pm 0.73$ & $1.21 \pm 0.56$ \\
\hline 103 & 5-Decanone & 1057.5 & 7.68 & $0.44 \pm 0.05$ & $0.30 \pm 0.08$ & $0.39 \pm 0.16$ & $0.07 \pm 0.01$ \\
\hline 104 & 5-Nonanone & 1076.7 & 7.956 & $0.28 \pm 0.02$ & $0.07 \pm 0.02$ & $0.22 \pm 0.04$ & $0.04 \pm 0.01$ \\
\hline 105 & 2-Nonanone & 1095.9 & 8.143 & $0.02 \pm 0.00$ & $0.03 \pm 0.01$ & $0.16 \pm 0.01$ & $0.02 \pm 0.00$ \\
\hline 106 & 5-Decanone isomer & 1176.3 & 9.06 & $0.05 \pm 0.00$ & $0.05 \pm 0.00$ & $0.02 \pm 0.00$ & $0.05 \pm 0.02$ \\
\hline 107 & 2-Decanone & 1195.5 & 9.231 & $0.04 \pm 0.00$ & $0.12 \pm 0.03$ & $0.16 \pm 0.01$ & $0.90 \pm 0.34$ \\
\hline 108 & Cyclononanone & 1249.5 & 9.666 & $0.01 \pm 0.01$ & $0.02 \pm 0.01$ & $0.05 \pm 0.01$ & $0.04 \pm 0.04$ \\
\hline 109 & Carvone ${ }^{*}$ & 1258.1 & 9.831 & - & - & - & $0.02 \pm 0.03$ \\
\hline 110 & 6-Undecanone & 1277.6 & 10.013 & $0.30 \pm 0.08$ & $0.30 \pm 0.05$ & $0.25 \pm 0.03$ & $0.76 \pm 0.22$ \\
\hline 111 & 6-Dodecanone & 1375.5 & 10.928 & $0.13 \pm 0.06$ & $0.63 \pm 0.17$ & $0.16 \pm 0.03$ & $0.48 \pm 0.08$ \\
\hline
\end{tabular}


Table 3. Cont.

\begin{tabular}{|c|c|c|c|c|c|c|c|}
\hline No. & Volatiles & KI & Rt (min) & WG & WE & RE & RRE \\
\hline & Total ketones & & & 3.77 & 2.50 & 5.37 & 3.69 \\
\hline & Lactones & & & & & & \\
\hline 112 & $\gamma$-Butyrolactone & 897 & 6.025 & $1.01 \pm 0.17$ & $1.43 \pm 1.98$ & $0.08 \pm 0.01$ & $0.02 \pm 0.00$ \\
\hline 113 & $\gamma$-Pentalactone & 945.1 & 6.548 & $0.51 \pm 0.09$ & $0.59 \pm 0.22$ & $0.53 \pm 0.11$ & $0.27 \pm 0.13$ \\
\hline 114 & $\gamma$-Caprolactone & 1059.9 & 7.775 & $1.14 \pm 0.16$ & $2.10 \pm 0.77$ & $2.14 \pm 0.42$ & $6.58 \pm 2.38$ \\
\hline 115 & $\gamma$-Heptalactone & 1161.8 & 8.87 & $0.09 \pm 0.01$ & $0.26 \pm 0.07$ & $0.19 \pm 0.01$ & $0.86 \pm 0.27$ \\
\hline 116 & $\gamma$-Octalactone & 1269.5 & 9.931 & $0.82 \pm 0.21$ & $1.33 \pm 0.14$ & $0.36 \pm 0.04$ & $2.77 \pm 1.07$ \\
\hline 117 & $\delta$-Octalactone & 1299.3 & 10.253 & $0.05 \pm 0.01$ & $0.06 \pm 0.01$ & $0.14 \pm 0.06$ & $0.14 \pm 0.04$ \\
\hline 118 & Isomintlactone & 1356.2 & 10.736 & $1.74 \pm 0.68$ & $4.34 \pm 1.03$ & $1.19 \pm 0.24$ & $8.31 \pm 1.60$ \\
\hline 119 & $\gamma$-Nonalactone & 1373.6 & 10.921 & $0.76 \pm 0.30$ & $2.49 \pm 0.26$ & $0.88 \pm 0.17$ & $4.20 \pm 0.55$ \\
\hline 120 & $\delta$-Nonalactone & 1402.5 & 11.246 & $0.03 \pm 0.02$ & $0.02 \pm 0.00$ & $0.13 \pm 0.05$ & $0.23 \pm 0.30$ \\
\hline 121 & Coumarin isomer & 1433.8 & 11.518 & $0.04 \pm 0.02$ & $0.23 \pm 0.04$ & $0.02 \pm 0.01$ & $0.03 \pm 0.03$ \\
\hline 122 & Coumarin * & 1451.3 & 11.702 & $7.28 \pm 3.33$ & $19.75 \pm 8.56$ & $1.14 \pm 0.30$ & $0.78 \pm 0.18$ \\
\hline \multirow[t]{3}{*}{123} & Herniarin & 1750.7 & 14.616 & $0.78 \pm 0.29$ & $1.37 \pm 0.88$ & $0.04 \pm 0.01$ & $0.07 \pm 0.02$ \\
\hline & Total lactones & & & 14.24 & 33.99 & 6.84 & 24.25 \\
\hline & Monoterpenes & & & & & & \\
\hline 124 & Limonene * & 1033.6 & 7.529 & $0.17 \pm 0.02$ & $0.48 \pm 0.11$ & $4.35 \pm 0.09$ & $0.07 \pm 0.03$ \\
\hline 125 & $p$-Cymene * & 1028.7 & 7.435 & $0.12 \pm 0.02$ & $0.06 \pm 0.03$ & $0.23 \pm 0.06$ & $0.16 \pm 0.06$ \\
\hline 126 & Thymol* & 1309.1 & 10.313 & $0.01 \pm 0.00$ & $0.01 \pm 0.00$ & $0.06 \pm 0.04$ & $0.24 \pm 0.06$ \\
\hline \multirow[t]{3}{*}{127} & $\alpha$-Terpineol * & 1084.2 & 8.106 & $0.02 \pm 0.00$ & $0.02 \pm 0.01$ & $0.10 \pm 0.02$ & $0.09 \pm 0.02$ \\
\hline & Total monoterpenes & & & 0.31 & 0.57 & 4.74 & 0.57 \\
\hline & Sesquiterpenes & & & & & & \\
\hline 128 & Cadalene & 1706 & 14.127 & - & - & $0.08 \pm 0.07$ & $0.03 \pm 0.03$ \\
\hline 129 & $\alpha$-Copaene & 1395 & 11.223 & $0.10 \pm 0.09$ & $0.05 \pm 0.02$ & $0.11 \pm 0.04$ & $0.16 \pm 0.13$ \\
\hline 130 & Longifolene & 1428.1 & 11.462 & $0.01 \pm 0.01$ & $0.03 \pm 0.00$ & $0.06 \pm 0.01$ & $0.04 \pm 0.01$ \\
\hline 131 & $\alpha$-Muurolene & 1507.2 & 12.269 & $0.01 \pm 0.00$ & $0.08 \pm 0.03$ & $0.11 \pm 0.05$ & $0.01 \pm 0.00$ \\
\hline \multirow[t]{3}{*}{132} & $\beta$-Caryophyllene * & 1437.2 & 11.537 & $0.01 \pm 0.01$ & $0.02 \pm 0.00$ & $0.04 \pm 0.01$ & $0.05 \pm 0.01$ \\
\hline & Total sesquiterpenes & & & 0.12 & 0.18 & 0.39 & 0.28 \\
\hline & Unidentified volatiles & & & & & & \\
\hline 133 & Unknown & 1305.4 & 10.393 & $0.01 \pm 0.00$ & $0.02 \pm 0.00$ & $0.01 \pm 0.00$ & $0.08 \pm 0.10$ \\
\hline 134 & Unknown & 1667.4 & 13.841 & $0.01 \pm 0.01$ & $0.02 \pm 0.02$ & $0.07 \pm 0.09$ & $4.98 \pm 7.03$ \\
\hline 135 & Unknown & 1821.9 & 15.264 & $0.18 \pm 0.13$ & $0.13 \pm 0.09$ & $0.09 \pm 0.04$ & $0.27 \pm 0.29$ \\
\hline \multicolumn{4}{|c|}{ Total unidentified volatiles } & 0.21 & 0.18 & 0.17 & 5.33 \\
\hline
\end{tabular}

$\mathrm{KI}=$ Kovats index, $\mathrm{Rt}=$ retention time. ${ }^{*}$ Denotes volatiles confirmed using authentic standards.

\subsubsection{Aldehydes/Ketones}

Aldehydes represented the major class of volatiles in specimens at ca. 37.34, 32.52, 44.60 and $19.48 \%$ in WG, WE, RE and RRE, respectively. Benzaldehyde (peak 36) was the most abundant aldehyde, being more enriched in RE samples (ca.18.71\%), followed by $(E$ )-cinnamaldehyde (peak 47 ), present in a relatively high amount at ca. 12.3, 11.2 and $7.2 \%$ in WE, RE and WG, respectively. The content of both aldehydes (peaks 36 and 47) was found at different levels among seed accessions, but most notably was found to decline upon roasting to reach 0.8 and $1.9 \%$, respectively. Benzaldehyde is known to account for the characteristic smell of bitter almonds produced as a result of amygdaline glycoside hydrolysis [32] and it likely to lead to a similar scenario in mahlab seeds. (E)Cinnamaldehyde exhibits a pungent cinnamon-like aroma and is likely to contribute to P. mahaleb seeds. The well-reported antimicrobial activity of $(E)$-cinnamaldehyde against a wide range of microorganisms [33] might contribute to the P. mahaleb seeds' use as an antidiarrheal agent in folk medicine.

Unlike aldehydes, ketones were detected at much lower levels in all specimens, ca. $3.7,2.5,5.3$ and $3.7 \%$ of the total volatiles in WG, WE, RE and RRE samples, respectively. Moreover, 3-Octen-2-one (peak 102) was the most abundant ketone, detected at the highest levels in WG and RE seeds ( 2.3 and $2.8 \%$, respectively). 


\subsubsection{Lactones}

Lactones constituted the second most abundant volatile class in mahlab seeds, with WE and WG yielding the highest levels (ca. 33.9 and $14.2 \%$, respectively), and they increased upon roasting, being detected in RE at $6.8 \%$ to reach $24.2 \%$ in RRE seeds. Such an increase is likely due to the dehydration impact of roasting to enhance the intramolecular lactonization of some compounds hydroxy fatty acids producing $\gamma$ and $\delta$-lactone compounds [34]. WE also encompassed, e.g., the highest fatty acid level, indicating that lactones originated from fatty acid cyclization. Among the identified lactones, $\gamma$-caprolactone (peak 114), isomintlactone (peak 118) and $\gamma$-nonalactone (peak 119) showed increases from 2.14, 1.19 and $0.88 \%$ to $6.58,8.31$ and $4.20 \%$, respectively, upon roasting in RE samples. Such observations can explain why the traditional use of mahlab seeds as flavoring agents in confections implies a short heating process to improve its sensory attributes, as evidenced by the increased lactone-derived aroma. $\gamma$-Caprolactone has sweet herbaceous notes [35], while isomintlactone and $\gamma$-nonalactone are characterized by mint-like [36] and coconut flavors [37], respectively.

Coumarin (peak 122) along with herniarin (7-methoxycoumarin) (peak 123) were found to be enriched in WE samples, at 19.75 and $1.37 \%$, respectively, compared to the other samples. Coumarin is well-known for its pleasant vanilla-like odor and slightly bitter taste and was previously reported in most parts of the P. mahaleb tree, i.e., leaves, fruits, seeds and wood, as well as in other plants, e.g., Melilotus alba and Cinnamonum verum [38]. Aside from their strong aroma, coumarins are reported to exhibit a wide range of biological actions, viz. antioxidant, anticancer, anti-inflammatory and antimicrobial actions [39]. However, hepatic damage and carcinogenic effects were also reported in experimental animals, limiting their potential use in humans. Accordingly, a tolerable daily intake of $0.1 \mathrm{mg} / \mathrm{kg}$ of body weight has been estimated based on human data experiments and recommended by the Scientific Panel on Food Additives, Flavorings, Processing Aids and Materials in Contact with Food (AFC) to guard against any hepatotoxicity [40]. Absolute quantification of coumarins in P. mahaleb should now follow, using standards in order ensure conclusive results.

\subsubsection{Acids/Esters}

The relative amounts of both organic and fatty acids detected in the aroma of white mahlab seeds obtained from Greece and Egypt and red Egyptian mahlab unroasted seeds were ca. $22.47,19.12$ and $17.43 \%$, respectively. Greek mahlab seeds, "WG", were the most abundant in acids, with valeric acid and its isomer (peaks 5 and 6) accounting for $9.2 \%$ among other acids. Valeric acid is a low-molecular-weight carboxylic acid with a very unpleasant odor, which commonly occurs in the valerian flowering plant [41]. It was previously reported in another Prunus species, namely Japanese apricot (P. mume) [42]; however, this is the first report of its detection in P. mahaleb. This acid is primarily used in the synthesis of esters to generate pleasant odors (fruity flavors) used in perfumes, cosmetics and food additives such as ethyl valerate and pentyl valerate [43]. The latter ester and its respective isomer (peaks 76 and 80) were detected at comparable levels as the most abundant esters at $1.6-1.9 \%$ in WG samples, respectively, and $1.2-1.6 \%$ in red Egyptian mahlab samples "RE", respectively, and are likely derived from valeric acid, also present in seeds. Other esters present at lower levels included pentyl caproate and n-butyl acetate (peaks 82 and 71 ) at 0.95 and $0.87 \%$, respectively, in WG samples. An increase in the pentyl caproate level in RE was observed upon roasting from 0.41 to $2.25 \%$, which would likely intensify its flavor.

Several short-chain fatty acids were identified, including butanoic acid, for the first time in P. mahaleb, reported before in apricot (P. armeniaca), in addition to caprylic and caproic acid, which were previously only reported in P. mume [42]. 


\subsubsection{Alcohols}

In contrast to aldehydes showing differences among specimens, alcohols were detected at comparable levels of 3-6\% in WG, WE, RE and RRE samples. In particular, 3-Octenol (peak 27), 1-hexanol (peak 25) and 2,3-butanediol (peak 23) represented the major forms in $\mathrm{RE}$ at ca. $1.62,1.45$, and $0.98 \%$, respectively, and decreased upon roasting $(0.97,0.07$ and $0.11 \%$, respectively); the exception was 1 -octanol (peak 28 ), which showed a predominance in roasted sample RRE at $3.2 \%$.

Moreover, 1-Hexanol (peak 25) was reported to impart green, sweet notes in lychee fruits and red wines, whereas pentanol (peak 22) was reported to contribute to the characteristic aroma of mahlab seeds [44].

\subsubsection{Furans}

Very low amounts of furan and its derivatives were detected, found at the highest levels in WG (5.41\%), followed by 2.4 and $3.8 \%$ in WE and RE samples, respectively. As expected, furan increased up to $6.37 \%$ upon roasting of RE samples, likely resulting from sugar oxidation in the seeds [45]. Furthermore, 2-Butylfuran (peak 95) and 2-pentylfuran (peak 96) were the most abundant furans in WG at 1.5 and 2.6\%, respectively. Furan and its derivatives, i.e., 2-alkylfurans, 2-acetylfuran, furfural and furfuryl alcohol, are produced via Maillard reaction in many heat-processed foods and beverages to contribute to their sensory properties. Furans can also serve as indicators of time-temperature effects during the production and storage of food items. In addition, 2-Akylfurans such as 2-butyl (peak 95) and 2-pentylfurans (peak 96) are mainly formed from lipid degradation [46], and some impart a mild, sweet and fruity taste, including 2-butylfuran, a constituent of many plant species and some cooked foods [47].

\subsubsection{Ethers}

Ethers were detected at trace levels $(0.01-0.05 \%)$, represented mostly by estragole (peak 90), a common flavor in many herbs and spices. Estragole, closely related to safrole, is a hepatotoxic and hepatocarcinogenic compound in experimental animals [48]; however, it is unlikely to exert any deleterious effects in P. mahaleb, being detected at such trace levels.

\subsubsection{Mono- and Sesquiterpene Hydrocarbons}

Mono- and sesquiterpenes amounted for 4.7 and $0.4 \%$ of the total volatiles in RE samples, found most enriched in the former compounds, suggesting that, in general, monoterpene biosynthesis is more strongly activated than that of sesquiterpenes in $P$. mahaleb. Mono- and sesquiterpenes were detected at $0.3-0.6 \%$ and $0.1-0.3 \%$ in other seeds, respectively. Limonene (peak 124) was the major monoterpene in RE, at $4.3 \%$, and it declined upon roasting to reach $0.1 \%$. Limonene is a key flavor in citrus fruits, with a pleasant lemon-like odor, aside from its several biological effects [49]. Its abundance in RE means that this specimen has the most favored aroma and it has yet to be evaluated using sensory analysis.

\subsubsection{Aliphatic Hydrocarbons}

Aliphatic hydrocarbons accounted for only $0.5-0.9 \%$ of the volatile composition in all seeds. Dodecane (peak 58), pentadecane (peak 59), tetradecane (peak 62) and hexadecane (peak 63) were prevalent, whereas heptadecane (peak 64) and nonadecane (peak 66) were detected at trace levels, previously identified in mahlab flower volatiles to serve as pheromones [50].

\subsubsection{Aromatics}

Among aromatics, naphthalene (peak 68), with its strong tar-like odor [51], was detected exclusively in roasted seeds, though at a low level of $2.7 \%$. Naphthalene and other PAHs (Polycyclic aromatic hydrocarbons) were reported to be formed during thermal food 
processing such as roasting, frying, grilling, toasting and smoking [52] and can thus be used as a marker for heat effects in P. mahaleb according to these results.

3.5. PCA Analysis of the Aroma Profiles of Unroasted White and Red Mahlab Seeds from Greece and Egypt

Heterogeneity in the volatile distribution of seed accessions was explored in a more holistic way using PCA, as in the primary plant metabolite dataset (Figure 4) [53].
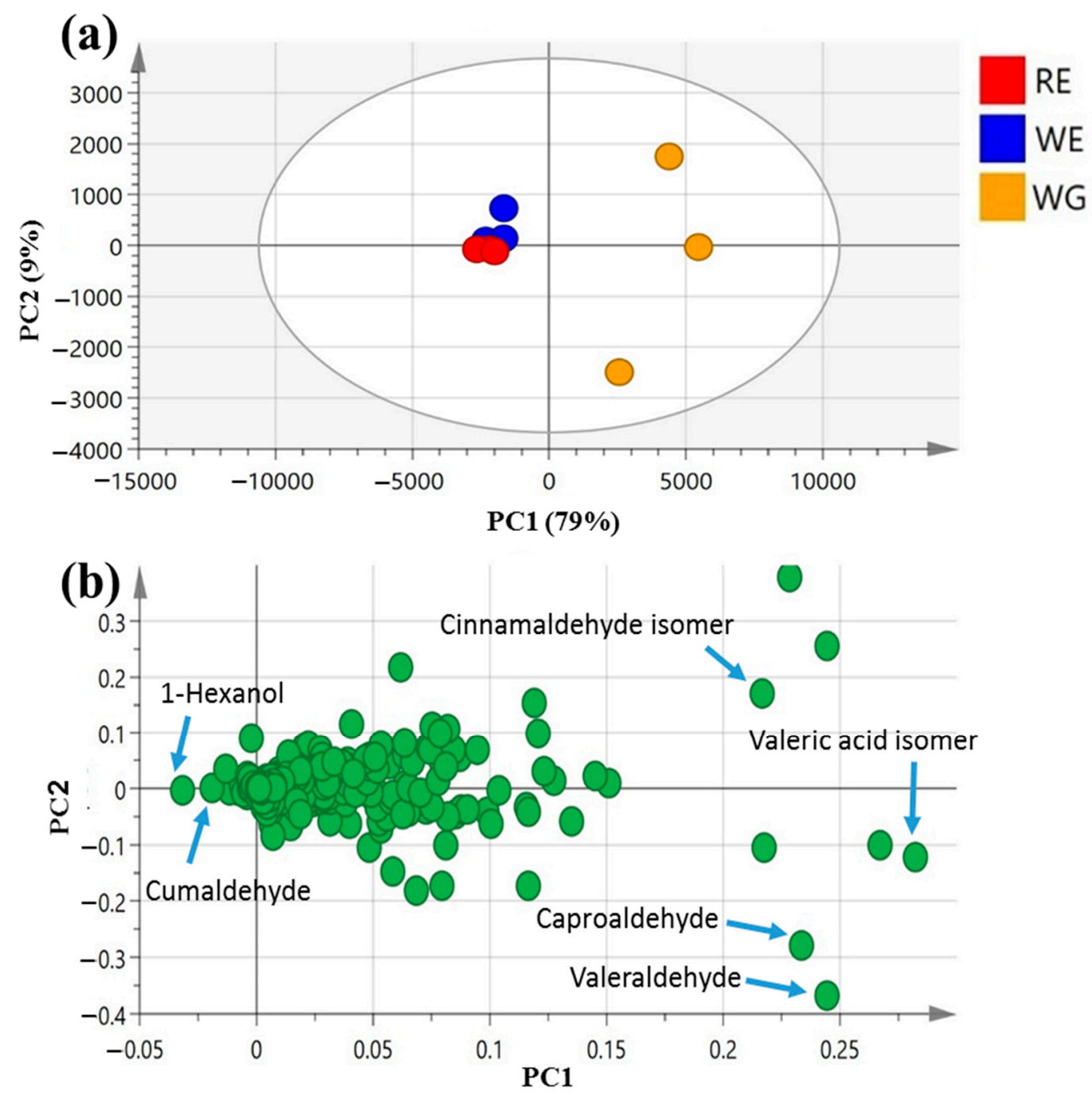

Figure 4. Unsupervised multivariate data analyses of the studied mahlab seeds derived from modeling volatile profiles analyzed via GC-MS ( $n=3$ ). (a) PCA score plot of PC1 vs. PC2 scores. (b) The respective loading plot for PC1 and PC2, providing their assignments. The metabolome clusters are placed in two-dimensional space at the distinct locations defined by two vectors of principal component PC1 $=79 \%$ and PC2 $=9 \%$.

PCA scores of the mahlab seed aroma profile (Figure 4a) were ascribed by two main vectors, i.e., $\mathrm{PC} 1$ and $\mathrm{PC} 2$, accounting for $88 \%$ of the total variance among samples. White WE and red RE mahlab seeds obtained from Egypt were clustered together along the negative side of PC1, apart from white Greek "WG", suggesting that geographical origin overcomes cultivar type with regard to the analyzed seeds' aromas.

The main volatiles responsible for specimens' segregation were revealed by the PCA loading plot (Figure $4 \mathrm{~b}$ ) to be 1-hexanol (peak 25) and cumaldehyde (peak 52), being most enriched in both WE and RE. In contrast, valeraldehyde (peak 29), with a pungent, bitter, almond-like odor [54] (peak 29); caproaldehyde, a with tallowy, green, leafy aroma [54] (peak 31) and isomeric forms of cinnamaldehyde (peak 47) and valeric acid (peak 6) pre- 
dominated among volatiles in mahlab seeds from Greece, suggesting that Greek specimens exhibited better aromas, being abundant in aldehydes.

\subsection{OPLS-DA Analysis of Unroasted versus Roasted Red Mahlab Seeds}

OPLS-DA modeling of the volatile profile of unroasted RE versus roasted red mahlab "RRE" seeds (Supplementary Figure S2) was attempted in order to assess the impact of roasting on their aroma as well as to identify roasting markers from the volatile dataset. The performance of the developed classification model was validated by the computed parameters "R2 (0.9621)" and "Q2 (0.9102)", which indicated the optimal fit and prediction power of the model, respectively, though with a $p$ value $>0.05$, suggestive of non-statistical significance.

The observed segregation in the derived score plot (Supplementary Figure S2a) was ascribed to the enrichment of unroasted RE in 1-hexanol (peak 25) and benzaldehyde (peak 36) versus the abundance of lactones, e.g., $\gamma$-caprolactone (peak 114) and isomintlactone (peak 118); furans, e.g., 1-(2-furyl)-3-butene-1,2-diol (peak 99), and a polyaromatic, i.e., naphthalene (peak 68) in roasted mahlab seeds, likely produced due to the applied high temperature during roasting (as depicted in S-plot, Supplementary Figure S2b). The production of lactones, furans and polyaromatic compounds is expected at high temperatures [55] and could indeed reveal the roasting impact on mahlab seed aroma.

\section{Conclusions}

The compositional heterogeneity in the primary and aroma metabolite profiles of $P$. mahlab seeds in the context of cultivar type and roasting is presented herein for the first time through a holistic untargeted GC-MS metabolomics coupled with multivariate data analyses.

The results of GC-MS analysis after silylation led to the detection of 65 peaks, including mostly sugars, fatty acids and acyl esters, with considerable amounts of glycerol, which increased post-roasting. Turanose was detected as the most abundant sugar in white cultivars from Greece and Egypt, while sucrose was predominant in all Sudanese specimens. Multivariate data analysis of the primary metabolome revealed that white mahlab from Egypt was the most distinct among accessions with the highest fatty acid level, viz., oleic and $\alpha$-linolenic acids, contributing to its fatty taste.

Around 135 volatiles were identified in mahlab seeds (roasted and unroasted) belonging to organic acids, aldehydes, alcohols, esters, furans, ketones, lactones, aliphatic hydrocarbons, aromatics and terpenes, with the first two classes most abundant in all seed accessions. White mahlab from Egypt showed the best aroma, being abundant in cinnamaldehyde (peak 47), concurrent with the highest lactone level, with a sweet taste that could compensate for its relatively low sugar content.

The selected mahlab resources in this study were collected from three countries that traditionally use mahlab and other worldwide varieties are yet to be included. Our approach is certainly applicable to the analysis of samples from such further sources for exploiting factors that might influence seed metabolic profile, i.e., seasonal variation, growth stage, storage and other processing conditions.

The most discriminating volatile class was aldehydes to distinguish seeds of different origin. With regard to volatile markers in the roasting process, 1 -octanol, $\gamma$-caprolactone and isomintlactone, as well as furans, e.g., 1-(2-furyl)-3-butene-1,2-diol and naphthalene, were enriched in the roasted seeds. A positive correlation was observed in all mahlab seed accessions among lactone level and fatty acids, likely via cyclization. Considering the lipid profile, white mahlab from Egypt presented the highest omega-3 to -6 ratio, with additional high levels of omega-9 oleic acid. Concurrent with its lower sugar composition, it has promise as a healthier food, especially for obese people.

An extended approach utilizing liquid chromatography coupled to mass spectrometry (LC-MS) can be applied to pinpoint differences in bioactive secondary metabolite profiles among mahlab seed accessions and to further elucidate the health effects of $P$. mahaleb. Our 
study provided the first complementary phytochemical evidence that supports the nutritional and flavor determinants of mahlab seeds, although it has yet to be complemented by other functional components of mahlab seeds to corroborate their utilization as functional foods or further as nutraceuticals.

Supplementary Materials: The following are available online at https:/ /www.mdpi.com/article/ 10.3390/foods10040728/s1, Figure S1: Representative SPME-GC-MS chromatograms of volatiles, collected from the extracts of (a) white mahlab from Greece "WG", (b) white mahlab from Egypt "WE", (c) red mahlab from Egypt "RE" and (d) roasted red mahlab from Egypt "RRE". Figure S2: GCMS based OPLS-DA score plot (a) derived from modeling aroma profile of unroasted red RE versus red roasted RRE mahaleb $(n=3)$. The respective loading S-plots $(b)$ showing the covariance $\mathrm{p}$ [1] against the correlation $\mathrm{p}$ (cor) [1] of the variables of the discriminating component of the OPLS-DA model. Designated variables are highlighted and identifications are discussed in the text.

Author Contributions: M.A.F. conceptualized the study; M.A.F. and S.S. performed the analysis; A.R.K. and S.M.A. identified the metabolites; M.A.F. revised the metabolites identification; A.R.K. and S.M.A. wrote the first draft; M.A.F. and A.R.K. performed the chemometry; M.A.F., A.R.K., S.M.A. wrote and revised the final manuscript. All authors have read and agreed to the published version of the manuscript.

Funding: This research received no external funding.

Acknowledgments: Mohamed A. Farag wishes to thank the American University in Cairo for assistance in GC-MS measurements and the Alexander von Humboldt foundation, Germany for the financial support.

Conflicts of Interest: The authors report no conflict of interest.

\section{References}

1. Gerardi, C.; Tommasi, N.; Albano, C.; Blando, F.; Rescio, L.; Pinthus, E.; Mita, G. Prunus mahaleb L. fruit extracts: A novel source for natural food pigments. Eur. Food Res. Technol. 2015, 241, 683-695. [CrossRef]

2. Mariod, A.A.; Aseel, K.M.; Mustafa, A.A.; Abdel-Wahab, S.I. Characterization of the seed oil and meal from monechma ciliatum and prunus mahaleb seeds. JAOCS J. Am. Oil Chem. Soc. 2009, 86, 749-755. [CrossRef]

3. Özçelik, B.; Koca, U.; Kaya, D.A.; Şekeroğlu, N. Evaluation of the in vitro bioactivities of mahaleb cherry (Prunus mahaleb L.). Rom. Biotechnol. Lett. 2012, 17, 7863-7872.

4. Shams, K.A. Chemical investigation of Prunus mahaleb L. kernels. J. Arab. Soc. Med. Res. 2006, 1, 176.

5. Shams, K.A.; Schmidt, R. Lipid fraction constituents and evaluation of anti-anaphylactic activity of Prunus mahaleb L. kernels. African J. Tradit. Complement. Altern. Med. 2007, 4, 289-293. [CrossRef]

6. Jerkovic, I.; Marijanovic, Z.; Staver, M.M. Screening of natural organic volatiles from prunus mahaleb L. honey: Coumarin and vomifoliol as nonspecific biomarkers. Molecules 2011, 16, 2507-2518. [CrossRef]

7. Afifi, S.M.; El-Mahis, A.; Heiss, A.G.; Farag, M.A. Gas Chromatography-Mass Spectrometry-Based Classification of 12 Fennel (Foeniculum vulgare Miller) Varieties Based on Their Aroma Profiles and Estragole Levels as Analyzed Using Chemometric Tools. ACS Omega 2021, 6, 5775-5785. [CrossRef]

8. Farag, M.A.; Fathi, D.; Shamma, S.; Shawkat, M.S.A.; Shalabi, S.M.; El Seedi, H.R.; Afifi, S.M. Comparative metabolome classification of desert truffles Terfezia claveryi and Terfezia boudieri via its aroma and nutrients profile. LWT 2021, $142,111046$. [CrossRef]

9. Garcia, C.; Pedro, J.; José, A.G. Contemporary pollen and seed dispersal in a Prunus mahaleb population: Patterns in distance and direction. Mol. Ecol. 2007, 16, 1947-1955. [CrossRef]

10. Farag, M.A.; Khattab, A.R.; Ehrlich, A.; Kropf, M.; Heiss, A.G.; Wessjohann, L.A. Gas Chromatography/Mass Spectrometry-Based Metabolite Profiling of Nutrients and Antinutrients in Eight Lens and Lupinus Seeds (Fabaceae). J. Agric. Food Chem. 2018, 66, 4267-4280. [CrossRef]

11. Farag, M.A.; Maamoun, A.A.; Ehrlich, A.; Fahmy, S.; Wesjohann, L.A. Assessment of sensory metabolites distribution in 3 cactus Opuntia ficus-indica fruit cultivars using UV fingerprinting and GC/MS profiling techniques. LWT 2017, 80, 145-154. [CrossRef]

12. AMDIS. Available online: http:/ / www.amdis.net (accessed on 28 November 2019).

13. Wang, R.; Bae, J.S.; Kim, J.H.; Kim, B.S.; Yoon, S.H.; Park, C.S.; Yoo, S.H. Development of an efficient bioprocess for turanose production by sucrose isomerisation reaction of amylosucrase. Food Chem. 2012, 132, 773-779. [CrossRef]

14. Park, M.O.; Lee, B.H.; Lim, E.; Lim, J.Y.; Kim, Y.; Park, C.S.; Lee, H.G.; Kang, H.K.; Yoo, S.H. Enzymatic Process for High-Yield Turanose Production and Its Potential Property as an Adipogenesis Regulator. J. Agric. Food Chem. 2016, 64, 4758-4764. [CrossRef]

15. Mcdaniel, K.A.; White, B.L.; Dean, L.L.; Sanders, T.H.; Davis, J.P. Compositional and Mechanical Properties of Peanuts Roasted to Equivalent Colors using Different Time/Temperature Combinations. J. Food Sci. 2012, 77. [CrossRef] 
16. Grembecka, M. Sugar alcohols—their role in the modern world of sweeteners: A review. Eur. Food Res. Technol. 2015, 241, 1-14. [CrossRef]

17. Croze, M.L.; Soulage, C.O. Potential role and therapeutic interests of myo-inositol in metabolic diseases. Biochimie 2013, 95, 1811-1827. [CrossRef]

18. Suiryanrayna, M.V.A.N.; Ramana, J.V. A review of the effects of dietary organic acids fed to swine. J. Anim. Sci. Biotechnol. 2015, 6 , 1-11. [CrossRef]

19. Pereira, C.; Barros, L.; Carvalho, A.M.; Ferreira, I.C.F.R. Use of UFLC-PDA for the Analysis of Organic Acids in Thirty-Five Species of Food and Medicinal Plants. Food Anal. Methods 2013, 6, 1337-1344. [CrossRef]

20. Connelly, W.M.; Errington, A.C.; Crunelli, V. $\gamma$-Hydroxybutyric acid (GHB) is not an agonist of extrasynaptic GABAa receptors PLoS ONE 2013, 8, e79062. [CrossRef]

21. Wan Isahak, W.N.R.; Che Ramli, Z.A.; Ismail, M.; Jahim, J.M.; Yarmo, M.A. Recovery and purification of crude glycerol from vegetable oil transesterification. Sep. Purif. Rev. 2015, 44, 250-267. [CrossRef]

22. Damasceno, N.R.T.; Pérez-Heras, A.; Serra, M.; Cofán, M.; Sala-Vila, A.; Salas-Salvadó, J.; Ros, E. Crossover study of diets enriched with virgin olive oil, walnuts or almonds. Effects on lipids and other cardiovascular risk markers. Nutr. Metab. Cardiovasc. Dis. 2011, 21. [CrossRef]

23. Madigan, C.; Ryan, M.; Owens, D.; Collins, P.; Tomkin, G.H. Dietary Unsaturated Fatty Acids in Type 2 Diabetes. Diabetes Care 2000, 23, 1472-1477. [CrossRef]

24. Blondeau, N.; Lipsky, R.H.; Bourourou, M.; Duncan, M.W.; Gorelick, P.B.; Marini, A.M. Alpha-linolenic acid: An omega-3 fatty acid with neuroprotective properties-Ready for use in the stroke clinic? Biomed Res. Int. 2015, 2015, 519830. [CrossRef] [PubMed]

25. Ruiz-León, A.M.; Lapuente, M.; Estruch, R.; Casas, R. Clinical advances in immunonutrition and atherosclerosis: A review. Front. Immunol. 2019, 10, 837. [PubMed]

26. Ding, S.; Yang, J. The influence of emulsifiers on the rheological properties of wheat flour dough and quality of fried instant noodles. LWT Food Sci. Technol. 2013, 53, 61-69. [CrossRef]

27. Lee, L.Y.; Chin, N.L.; Lim, C.H.; Yusof, Y.A.; Talib, R.A. Saturated Distilled Monoglycerides Variants in Gel-form Cake Emulsifiers. Agric. Agric. Sci. Procedia 2014, 2, 191-198. [CrossRef]

28. Sose, M.T.; Bansode, S.R.; Rathod, V.K. Solvent free lipase catalyzed synthesis of butyl caprylate. J. Chem. Sci. 2017, 129, 1755-1760. [CrossRef]

29. Saba, A.; Benini, O.; Cupisti, A. Technical Aspects About Measuring Phosphorus in Food. In Clinical Aspects of Natural and Added Phosphorus in Foods; Springer: New York, NY, USA, 2017; pp. 133-141.

30. Farag, M.A.; Gad, H.A.; Heiss, A.G.; Wessjohann, L.A. Metabolomics driven analysis of six Nigella species seeds via UPLC-qTOFMS and GC-MS coupled to chemometrics. Food Chem. 2014, 151, 333-342. [CrossRef]

31. El Hadi, M.A.M.; Zhang, F.J.; Wu, F.F.; Zhou, C.H.; Tao, J. Advances in fruit aroma volatile research. Molecules 2013, 18, 8200-8229.

32. Sánchez-Pérez, R.; Howad, W.; Garcia-Mas, J.; Arús, P.; Martínez-Gómez, P.; Dicenta, F. Molecular markers for kernel bitterness in almond. Tree Genet. Genomes 2010, 6, 237-245. [CrossRef]

33. Burt, S. Essential oils: Their antibacterial properties and potential applications in foods-A review. Int. J. Food Microbiol. 2004, 94, 223-253. [CrossRef] [PubMed]

34. Obi, J.; Yoshinaga, K.; Tago, A.; Nagai, T.; Yoshida, A.; Beppu, F.; Gotoh, N. Simple quantification of lactones in milk fat by solvent extraction using gas chromatography- mass spectrometry. J. Oleo Sci. 2018, 67, 941-948. [CrossRef]

35. Dellacassa, E.; Trenchs, O.; Fariña, L.; Debernardis, F.; Perez, G.; Boido, E.; Carrau, F. Pineapple (Ananas comosus L. Merr.) wine production in Angola: Characterisation of volatile aroma compounds and yeast native flora. Int. J. Food Microbiol. 2017, 241, 161-167. [CrossRef]

36. Picard, M.; de Revel, G.; Marchand, S. First identification of three p-menthane lactones and their potential precursor, menthofuran, in red wines. Food Chem. 2017, 217, 294-302. [CrossRef]

37. Stensmyr, M.C.; Erland, S.; Hallberg, E.; Wallén, R.; Greenaway, P.; Hansson, B.S. Insect-like olfactory adaptations in the terrestrial giant robber crab. Curr. Biol. 2005, 15, 116-121. [CrossRef]

38. Ieri, F.; Pinelli, P.; Romani, A. Simultaneous determination of anthocyanins, coumarins and phenolic acids in fruits, kernels and liqueur of Prunus mahaleb L. Food Chem. 2012, 135, 2157-2162. [CrossRef]

39. Fylaktakidou, K.; Hadjipavlou-Litina, D.; Litinas, K.; Nicolaides, D. Natural and Synthetic Coumarin Derivatives with AntiInflammatory/Antioxidant Activities. Curr. Pharm. Des. 2005, 10, 3813-3833. [CrossRef]

40. Opinion of the Scientific Panel on food additives, flavourings, processing aids and materials in contact with food (AFC) related to Coumarin. EFSA J. 2004, 2. [CrossRef]

41. Bajpai, A.K.; Dwivedi, A.; Pandey, A.K. Comparative Study of structural, vibrational, electronic properties of pentanoic acid (Valeric acid) and its derivative 4-oxopentanoic acid (Levulinic acid) by Density Functional Theory. J. Sci. Res. Adv. 2014, 1, 18-24. Available online: www.jsciresadv.weebly.com (accessed on 22 September 2020).

42. Poonam, V.; Kumar, G.; SReddy, L.; C Jain, R.; K Sharma, S.; K Prasad, A.; S Parmar, V. Chemical Constituents of the Genus Prunus and their Medicinal Properties. Curr. Med. Chem. 2012, 18, 3758-3824. [CrossRef]

43. Iqbal, Z. Fatty acid profile of aerial roots of ficus elastic. World J. Pharm. Res. 2017, 54-60. [CrossRef] 
44. Ozturk, I.; Karaman, S.; Baslar, M.; Cam, M.; Caliskan, O.; Sagdic, O.; Yalcin, H. Aroma, Sugar and Anthocyanin Profile of Fruit and Seed of Mahlab (Prunus mahaleb L.): Optimization of Bioactive Compounds Extraction by Simplex Lattice Mixture Design. Food Anal. Methods 2014, 7, 761-773. [CrossRef]

45. Yaylayan, V.A. Precursors, formation and determination of furan in food. J. Verbraucherschutz Leb. 2006, 1, 5-9. [CrossRef]

46. Min, D.B.; Callison, A.L.; Lee, H.O. Singlet oxygen oxidation for 2-pentylfuran and 2-pentenyfuran formation in soybean oil. J. Food Sci. 2003, 68, 1175-1178. [CrossRef]

47. Shen, M.; Liu, Q.; Jia, H.; Jiang, Y.; Nie, S.; Xie, J.; Li, C.; Xie, M. Simultaneous determination of furan and 2-alkylfurans in heat-processed foods by automated static headspace gas chromatography-mass spectrometry. LWT Food Sci. Technol. 2016, 72, 44-54. [CrossRef]

48. Rietjens, I.M.C.M.; Cohen, S.M.; Fukushima, S.; Gooderham, N.J.; Hecht, S.; Marnett, L.J.; Smith, R.L.; Adams, T.B.; Bastaki, M.; Harman, C.G.; et al. Impact of structural and metabolic variations on the toxicity and carcinogenicity of hydroxy- and alkoxy-substituted allyl- and propenylbenzenes. Chem. Res. Toxicol. 2014, 27, 1092-1103. [CrossRef] [PubMed]

49. Vieira, A.J.; Beserra, F.P.; Souza, M.C.; Totti, B.M.; Rozza, A.L. Limonene: Aroma of innovation in health and disease. Chem. Biol. Interact. 2018, 283, 97-106. [CrossRef] [PubMed]

50. Mastelić, J.; Jerković, I.; Mesić, M. Volatile constituents from flowers, leaves, bark and wood of Prunus mahaleb L. Flavour Fragr. J. 2006, 21, 306-313. [CrossRef]

51. Price, P.S.; Jayjock, M.A. Available data on naphthalene exposures: Strengths and limitations. Regul. Toxicol. Pharmacol. 2008, 51, 15-21. [CrossRef]

52. Cao, X.L.; Hierlihy, T.; Popovic, S.; Dabeka, B. Headspace solid-phase microextraction with gas chromatography-mass spectrometry determination of naphthalene in the composite food samples from the 2011 canadian total diet study in ottawa. J. Food Prot. 2012, 75, 2163-2171. [CrossRef] [PubMed]

53. Farag, M.A.; Khattab, A.R.; Maamoun, A.A.; Kropf, M.; Heiss, A.G. UPLC-MS metabolome based classification of Lupinus and Lens seeds: A prospect for phyto-equivalency of its different accessions. Food Res. Int. 2019, 115, 379-392. [CrossRef] [PubMed]

54. Jelen, H.H. Solid-phase microextraction in the analysis of food taints and off-flavors. J. Chromatogr. Sci. 2006, 44, 399-415. [CrossRef] [PubMed]

55. Wei, F.; Tanokura, M. Chemical Changes in the Components of Coffee Beans during Roasting. In Coffee in Health and Disease Prevention; Academic Press: London, UK, 2015; pp. 83-91. ISBN 9780124167162. 